\title{
Performance Improvement of Reluctance Synchronous Motor Using Brain Emotional Learning Based Intelligent Controller
}

\author{
Mehrdad Ahmadi Kamarposhti ${ }^{1, *(\mathbb{D}}$, Hassan Shokouhandeh ${ }^{2}$, Ilhami Colak ${ }^{3}$ and Kei Eguchi $^{4}(\mathbb{D}$ \\ 1 Department of Electrical Engineering, Jouybar Branch, Islamic Azad University, Jouybar, Iran \\ 2 Department of Electrical Engineering, Semnan University, Semnan 35131-19111, Iran; \\ shokouhandeh@semnan.ac.ir \\ 3 Department of Electrical and Electronics Engineering, Faculty of Engineering and Architectures, \\ Nisantasi University, Istanbul 25370, Turkey; ilhcol@gmail.com \\ 4 Department of Information Electronics, Fukuoka Institute of Technology, Fukuoka 811-0295, Japan; \\ eguti@fit.ac.jp \\ * Correspondence: mehrdad.ahmadi.k@gmail.com or m.ahmadi@jouybariau.ac.ir
}

Citation: Ahmadi Kamarposhti, M.; Shokouhandeh, H.; Colak, I.; Eguchi, K. Performance Improvement of Reluctance Synchronous Motor Using Brain Emotional Learning Based Intelligent Controller. Electronics 2021, 10, 2595. https://doi.org/10.3390/ electronics10212595

Academic Editor: M. Tariq Iqbal

Received: 6 September 2021

Accepted: 21 October 2021

Published: 24 October 2021

Publisher's Note: MDPI stays neutral with regard to jurisdictional claims in published maps and institutional affiliations.

Copyright: (C) 2021 by the authors. Licensee MDPI, Basel, Switzerland. This article is an open access article distributed under the terms and conditions of the Creative Commons Attribution (CC BY) license (https:// creativecommons.org/licenses/by/ $4.0 /)$.

\begin{abstract}
In this paper, intelligent control of a reluctance synchronous motor by an emotional controller, considering the effect of magnetic saturation on implementation, is analyzed; the maximum torque per ampere (MTPA) strategy is provided. According to the application of the proposed control scheme, the structure adequately performs the control of speed and magnetic flux of the reluctance synchronous motor drive. Additionally, the application of intelligent control based on an emotional learning system has provided adequate results to create a proper control process. The control function of a SynRM drive based on vector control in a rotor machine was compared with another based on emotional controllers and a PI controller regulated by genetic algorithms. The result of this comparison was the improvement of control functions by the controller based on the emotional controller. In addition, the MTPA based on search algorithms was well implemented in different situations. Due to its simplicity and independence from system parameters, the emotional controller can be considered as a potential operational method in the industry.
\end{abstract}

Keywords: intelligent control; reluctance synchronous motor; emotional controller; maximum torque per ampere; magnetic saturation

\section{Introduction}

The presence of electric-powered machines has created a huge transformation worldwide, which is reflected in other industrial and scientific fields. After enhancing power electronics and control engineering, AC drives have become more common than DC drives. Among AC machines, induction machines are often used as motors, and synchronous machines are often used as generators. After the development of drive control science, synchronous motors have also gradually entered the motorized area, which is also expanding with the presence of permanent proper magnet materials and the design of permanent magnet machines (PMSMs). However, some special electric motors have been developed that have interesting designs, including the reluctance synchronous motor. This motor, which has attracted more attention since advancements have been made in the science of designing the mechanical structure of vehicles, can operate in a synchronous motor mode without any electrical or magnetic circuits in the rotor structure. Based on the structure of this motor, which can be used in a rotor as a cog-induced machine, the machine starts to move as an induction during start up and then enters the synchronous work area by the torque of the reluctance. Because of the simple structure and the lack of energy losses in the rotor circuit, it is supposed that, in the future, many drive applications will move towards the use of these machines. It should be noted that the changes in saturation due to the performance of the reluctance on the magnetic elements are high, and this causes 
changes in these elements during the operation of the system. Therefore, controlling this drive requires the use of regulated controllers. However, today, the problem of energy conservation is a determining factor for electrical devices. Due to changes based on motor saturation, the MTPA search algorithm has been proposed to increase efficiency. This algorithm seeks to find the proper amount of magnetic flux that, despite providing the least reactive power to generate torque, minimizes losses of saturation and ohms. From the controller's point of view, in the proposed structure, based on vector control, an emotional controller is proposed because of its relatively simple but efficient structure. Emotional control, which is modeled on the emotional increases of the mammalian brain, has its own unique characteristics compared to other types of control systems. Traditional neural networks are trained using large amounts of data, and these then control the system. This procedure has two main challenges: first, there is the need for a large amount of information for training, and secondly, this training is generally done off-line and, moreover, for practical implementation, it requires a system that has high hardware costs. Fuzzy logic-based controllers can also be practical tools for system control, but the performance of fuzzy logic-based controllers depends on membership functions (MFs) and rules. If MFs and fuzzy rules are not properly selected, fuzzy controllers may not perform satisfactorily. Additionally, these systems can be complicated in the implementation of the operating system, and so the cost of using advanced processors for the user is imposed, whereas emotional-based controllers with simple structures have automated training. A system that produces a control signal based on the principle of stress reduction in the human brain's Limbic system can be utilized. One of the issues involved in this type of controller is the design of sensory input functions and reinforcement signals based on control objectives. In this paper, a new emotional-based controller is proposed for controlling the flux and speed of a reluctance synchronous motor. In the second part of this paper, the methods of control of the reluctance synchronous motor are investigated. In the third section, a review of studies regarding the subject of the paper is carried out. In the fourth section, the mathematical model and the strategy of controlling the maximum torque per ampere (MTPA) of the reluctance synchronous motor is presented. In the fifth section, the control model and a smart controller based on the emotional learning of the brain will be explained. In the sixth section, the vector control of the velocity of the reluctance synchronous motor drive is provided by implementing the maximum torque per ampere. In the seventh section, the simulation results are presented in relation to the two scenarios. Finally, this paper concludes in section eight by providing the results. The main contribution of this paper is as follow:

- A new innovative smart emotional controller is proposed for magnetic flux and velocity control.

\section{Methods of Controlling the Reluctance Synchronous Motor}

The reluctance synchronous motor torque is proportional to the two-axis stator currents in the reference of the rotor frame $\left(i_{d s}, i_{q s}\right)$. Under a control method called constantcurrent vector control in the d-axis, the current, $i_{d s}$, can be kept constant and the torque can be controlled by changing the current of the q axis. Therefore, the torque with the current of the $q$ axis will have a linear relation similar to DC machines, and rapid torque changes can be made by applying rapid changes in the q-axis current, typically by applying a current-controlled pulse width modulation inverter. However, after the invention of vector control techniques in the late 1970s, independent torque and magnetic flux control was provided for all types of electric motor, but this possibility could not be realized under flux transit conditions. In addition, the high dependence on machine parameters and the need for transmitting coordinate devices and additional regulators for controlling motor currents encouraged researchers to use direct torque control (DTC) rather than vector control. The direct torque control method was first proposed by Mr. Takahashi in 1986 [1]. Using this method, it is possible to achieve the proper torque control function without the need for a mechanical position sampler with speed. The basis of the DTC method lies in 
limiting the torque and fluctuation error in relation to their reference values in a hysteresis band; in this method, conventional current regulators in vector control, transmission of coordinate devices, and PWM inverters (with specified timing) are not necessary and have less sensitivity to changing parameters. At the same time, DTC provides torque control in the flux transient and stable conditions. On the other hand, the classical DTC method has the following disadvantages [2]:

- The complexity of controlling flux and torque at very low speeds;

- High diversity in torque, flux, and stator currents;

- Variable switching frequencies;

- High disturbance at low speeds;

- Impossibility of the direct control of the current.

In addition to the recent cases, in the classic DTC method, a high sampling frequency is required to achieve the proper torque control function and limit the flux and torque error in a given band, and also to estimate them. On the other hand, the switching frequency of the inverter, which varies according to the speed of the drive and the ranges of error and depends on the hysteresis bandwidth, is small compared to the sampling frequency of the system. For example, with a $40 \mathrm{kHz}$ sampling frequency, a $3 \mathrm{kHz}$ switching frequency can be achieved in the inverter [2]. Although, in the low error range, the switching frequency increases, its non-constant nature makes filter design to remove the harmonics and ensure better sampling of the current more difficult. In addition, the torque currents are noteworthy due to the non-stimulated state caused by the application of the zero vector in launching conditions or transient states.

Over the last few decade, extensive research has been carried out to improve the above-mentioned problems. The use of modified switch tables [3], the modification of switching patterns [4], the modification of comparators with and without the hysteresis of two and three levels [5], the application of fuzzy and neuro-fuzzy methods [6], the use of modified estimators of flux to improve their performance at low speeds [7], and finally, applying PWM and space vector modulation (SVM) based methods to stabilize the switching frequency [8] have all been proposed.

In SVM-based direct torque control, at each switching period, the calculation of the stator's spatial voltage vector is carried out in a way that completely compensates the errors of torque and stator flux. To implement this method, the control system should be able to generate the desired voltage vector using the spatial vector modulation technique. The advantages of DTC-SVM can be expressed as following the classical method:

1. Reducing torque in steady state due to increase switching frequency;

2. Reducing the sampling frequency of the current and simplifying the sampler filter due to the constant switching frequency;

3. Simple implementation to limit inverter current; as mentioned, one of the disadvantages of direct torque control is the impossibility of direct control of the current. In this method, using the reference voltage obtained by the controller, the motor current is predicted, and if these currents are greater than the permitted value, the voltage recalculation is made in such a way that the current is within the permissible range;

4. The ability to control flux at very low speeds, which the classic DTC method is unable to do in that range.

With the above advantages, the DTC-SVM method has more computational volume than the classic DTC. Therefore, PWM-based converters still have a particular priority in the industry due to their simple structure and low cost. Regarding the nonlinear nature of electric machines, if the vector of the stator reference voltage is produced by nonlinear controllers, a more favorable performance of the electric drive is obtained. Over the past two decades, the method of input-output linearization in electric drives has been used [9-13].

This method is based on the direct connection between input and output through the use of differential geometry theorems and the elimination of nonlinear properties and, as 
has been specified, it has its own specific complexities. Even intelligent control methods, including fuzzy control, have been well implemented [14], but the important point to be considered along with the responsiveness of these advanced methods is their complexity, which can also increase the cost of hardware.

Finally, considering the approach of this paper, providing a proper structure, both in terms of performance and cost of implementing these methods, can be challenging. On the other hand, conventional PID controllers, which today are widely used in the industry, should be reviewed. The conventional PID controller, with its very simple structure, also has significant weaknesses. Adjusting the controller's coefficients can be considered as one of these challenges. Although system model-based methods are suitable for adjusting parameters, they do not work in nonlinear systems. With the advent of evolutionary methods, algorithms such as the particle swarm optimization algorithm (PSO) and genetic algorithm (GA) have been presented for adjusting the controllers' parameters. However, some of the optimization algorithms have weaknesses, which are mentioned in the next section.

\section{A Review of the Research Background}

The authors in [15] discuss in detail the development of controlling the reluctance synchronous motor for electric vehicles in which iron losses and magnetic saturation are neglected, where the control of this motor is largely influenced by these two phenomena. The exact expression of the saturation effects requires full knowledge of the magnetic behavior along the two axes, $\mathrm{d}$ and $\mathrm{q}$, of the rotor and their interactions at different operating points. Due to the high reluctance in the q-axis, in many papers, magnetic saturation is considered only in line with $\mathrm{d}$. In [16], the iron losses of the reluctance synchronous motor have been studied by adding a parallel resistance to its two-axial equivalence circuit, and various control strategies regarding saturation and iron losses are discussed. The iron losses cause coupling between the $\mathrm{d}$ and $\mathrm{q}$ axes and affect the transient performance of the machine. In the previous work, the authors have tried to compensate for the effect of iron losses and to eliminate the coupling between the $\mathrm{d}$ and q axes. In [17], a review was carried out on reluctance motor drive advancement. In this paper, the effects of magnetic saturation on the reluctance motor of the d-axis in terms of axis current, $i_{d}$, are considered in the form of a table and mathematical equations, while the inductance is assumed to be in line with the constant q, and the iron losses are based on a non-load test in the frequency, and different voltages are measured. In some cases, comparative methods such as the recursive least-squares method have been used to estimate on-line machine parameters based on voltage measurement and terminal current [18]. So far, many papers have been published on the direct control of the torque of the induction motors, but less attention has been paid to the DTC of reluctance synchronous motors [19]. In [20], a vector control is proposed for a synchronous reluctance motor. In this paper, intelligent controllers are used. As a result, the response of the system and the response to turbulence in the torque of load are not satisfactory. To overcome this problem, in [21] a comparative backward controller is proposed. Thus, the transient response and the ability to eliminate the effects of load turbulence were clearly improved. However, due to the use of the classical DTC in which the switching states are determined based on hysteresis bonding, the switching frequency varies, and torque, flux, and stator currents have a significant amount of beats. In recent years, extensive research has been carried out to provide DTCs with spatial vector modulation (DTC-SVM), which has a constant switching frequency [22]. In [23], sensitivity analysis and the optimal design of a synchronous reluctance motor was carried out. In this paper, a direct control method was provided based on a mathematical model of the rotor coordinate system, which has a constant switching frequency and a relatively long sampling time. In [24], a second-order sliding mode control based on a neural network was proposed. Although the sliding mode control method in the direct control of the torque of the reluctance synchronous motor drive without sampler of the position, even at very low 
and zero speeds, has shown good performance, its dependence on the machine parameters, in particular, biaxial inductances, makes practical implementation difficult.

In [25], an input-output linearization controller is used to direct control of the torque of a reluctance synchronous motor with high dynamic behavior, considering an optimal efficiency control strategy. In this method, instead of the stator flux, the criterion for establishing the strategy, which is explained based on Lagrange's theorem, is selected as one of the control outputs, and the product of the torque currents is selected as the other output. The impossibility of independent control of the flux domain and the need to know the exact values of the parameters are the disadvantages of this method. In addition, in [25], two PI controllers, whose coefficients must be adjusted properly, are also used.

In order to improve the behavior of the electric drive in relation to the changes of the electrical parameters and the reduction of torque ripple, there must be a strategy of direct control of the flux and torque of the induction motor on the control of the variable structure or sliding mode. Using the SVM inverter, the switching frequency was kept constant [26]. This robust method has a fast dynamic response, and its implementation is easy and there is less diversity in torque and stator flux. In this paper, a controller consisting of a combination of a switching component or a slippery mode with a PI regulator has been designed in the stator flux and used for both torque and flux. Due to the need to transfer coordinates from the static reference device to the stator flux reference system, and vice versa, the volume of calculations is high. To overcome this problem, a DTC-VSC-based permanent magnet synchronous motor drive was provided in a static coordinate system [27]. In addition, to estimate the stator flux, a closed loop estimator based on a sliding observer was used, and it was possible to estimate the rotor position. Although the proposed method eliminates two PI regulators of torque and flux and reduces the volume of computations, it ignores iron losses and does not consider any specific control function.

The exact rotor position must be known for field oriented control (FOC) and direct torque control in the rotor frame of the reluctance synchronous motor. The presence of a mechanical sampler of position reduces drive reliability and increases cost, volume, and noise sensitivity. On the other hand, in comparison with the induction motor, the rotor of the reluctance synchronous motor is prominent, which makes it possible to detect the position of the rotor, even at zero speed because, unlike the induction motor, the inductance of each phase is a function of the rotor position [28]. In [29], the mathematical modeling of an adaptive network-based fuzzy inference system (ANFIS) controller for a synchronous reluctance motor is carried out. The performance of the ANFIS controller is compared with PI and fuzzy controllers. The results indicate the better performance of the ANFIS controller compared to two other methods. In [30], an intelligent genetic neural network controller is proposed for minimizing a synchronous reluctance motor torque ripple. Simulation results show that, by using the proposed hybrid controller, the torque ripples vary between $3.25 \%$ and $1.7 \%$. In [31], an intelligent proportional-integral (iPI) controller is proposed for a synchronous reluctance motor for the control of torque and speed. The experimental results show that the iPI has high performance during dynamic loading compared to the traditional PI controller. In [32], the optimal design of a synchronous reluctance motor for an electric vehicle by genetic algorithm (GA) is carried out. The simulation results indicate that the motor performance improved, and the torque ripple is less than $8 \%$. In [33], topology optimization (TO) is proposed for design optimization of a synchronous reluctance machine for iron-loss reduction and torque improvement. In this paper, the adjoint variable technique is used for a sensitivity analysis of iron loss.

The main drawback of the reviewed papers is that they either used a controller with a complex structure or had difficulty in finding the optimum parameters of the controller. In this paper, a PWM based converter is proposed that includes specifications regarding the simplicity of the structure and the ability to change parameters and be adaptable to different working conditions, and which has a drive structure based on an emotional controller. 


\section{Mathematical Model and Strategy for Controlling the Maximum Torque per Ampere (TPA) of a Reluctance Synchronous Motor}

In this section, the two-axis model of a reluctance synchronous motor in the rotor reference system, considering iron losses and magnetic saturation, is presented, and the controlling strategy of this motor through the gradient method is investigated.

\subsection{Mathematical Model of Reluctance Synchronous Motor, Considering Iron Losses}

The dynamic model of a three-phase reluctance synchronous motor in a synchronous rotary reference machine is presented with the following assumptions:

- The slot effects of stator and rotor are neglected

The interaction between the rotor sheets and the stator slots of the reluctance synchronous machine leads to the creation of ripple in the produced torque. This effect can be calculated by assuming a constant angle of stator current with respect to the direct axis of the rotor and then rotating the rotor and measuring torque. Figure 1 shows the result of this experiment for a six-kilowatt reluctance synchronous machine of an axially laminated anisotropic (ALA) type using the stator of an induction machine of 36 slots [34]. Ripple peak-to-peak torque is about $10 \mathrm{~N} . \mathrm{m}$, while the torque is calculated from the nonlinear model of this machine in the angle of current of 36.4 N.m.

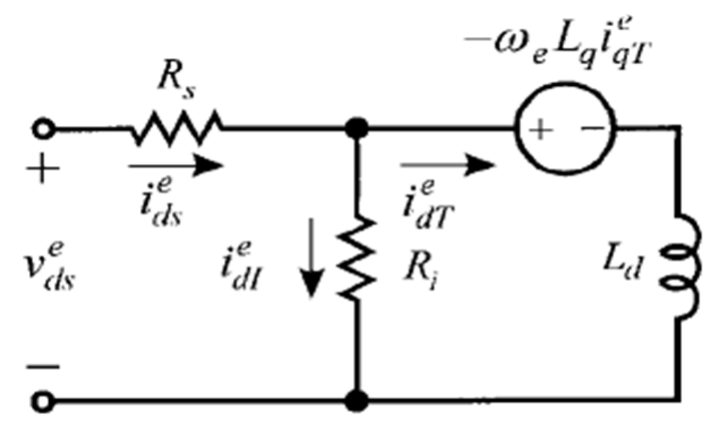

(a)

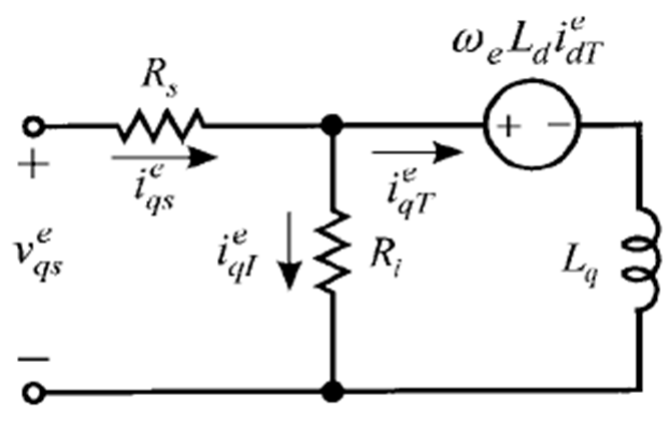

(b)

Figure 1. Biaxial equivalent circuit of a reluctance synchronous motor by considering iron losses: (a) axis d, (b) axis q adopted from [34].

This issue was clear, because neither rotor nor stator was built skewed. In rotors of the ALA type, a skewed rotor is not practical; therefore, it is necessary for the stator to be built skewed. If a TLA design is used for the rotor, then it is possible to tilt the rotor to minimize torque ripple. With the precise design of the rotor, it is possible for the torque ripple to be lowered sufficiently for a reluctance synchronous machine to be suitable for high performance service applications.

- $\quad$ The harmonic effects of the pulse width modulation inverter are neglected.

- The iron losses on the rotor side is neglected (because, according to the two assumptions, rotor synchronous mode and air gap flux both rotate with synchronous speed and therefore reside relative to each other).

- Transmission of resistance branch is equal to the iron losses before the stator leak inductance for ease of modeling.

Biaxial magnetization inductances with their corresponding leakage inductances are sequenced, and the biaxial equivalent circuit of the reluctance synchronous motor by considering loss of iron in the synchronous rotary reference machine is shown in Figure 1.

The resistance, $R_{i}$, explains the iron losses, which is considered as a parallel branch in both axis models. Due to this equivalent circuit, the electromagnetic torque produced by the motor, which is proportional to the product of the bonding flux and the currents, is not 
a function of the terminal currents, $i_{d s}^{e}$, and $i_{q s}^{e}$, but it is directly calculated from the $i_{d T}^{e}$ and $i_{q T}^{e}$ torque currents.

$$
T_{e}=\frac{3}{2} \frac{P o}{2} \cdot\left(\lambda_{d s} \cdot i_{q T}^{e}-\lambda_{q s} \cdot i_{d T}^{e}\right)=\frac{3}{2} \frac{P}{2} \cdot\left(L_{d}-L_{q}\right) \cdot i_{d T}^{e} \cdot i_{q T}^{e}=K_{T} i_{d T}^{e} i_{q T}^{e}
$$

where $P o$ is the number of poles, $L_{d}$ and $L_{q}$ are the biaxial inductances of the motor, and $\lambda_{d s}$ and $\lambda_{q s}$ are the biaxial bond fluxes of the stator. It is important to recall that the electromagnetic torque only includes the component of the reluctance, which is created due to the difference of the two-axis inductances $d$ and $q$. According to Figure 1 and using Kirchhoff's Voltage Law (KVL) and Kirchhoff's Current Law (KCL), the relation between stator currents and currents $i_{d T}^{e}$ and $i_{q T}^{e}$ can be calculated by Equation (2).

$$
\left[\begin{array}{c}
i_{d s}^{e} \\
i_{q s}^{e}
\end{array}\right]=\left[\begin{array}{cc}
\left(1+\mathrm{p} \frac{L_{d}}{R_{i}}\right) & -\frac{\omega L_{q}}{R_{i}} \\
\frac{\omega L_{d}}{R_{i}} & \left(1+\mathrm{p} \frac{L_{q}}{R_{i}}\right)
\end{array}\right]\left[\begin{array}{c}
i_{d T}^{e} \\
i_{q T}^{e}
\end{array}\right]
$$

where $p$ is a derivative operator. The inverse of the above equation is expressed as follows:

$$
\left[\begin{array}{c}
i_{d T}^{e} \\
i_{q T}^{e}
\end{array}\right]=\frac{R_{i}}{\left(\mathrm{~d} / \mathrm{dt}+R_{i} / L_{d}\right)\left(\mathrm{d} / \mathrm{dt}+R_{i} / L_{q}\right)+\omega_{e}^{2}}\left[\begin{array}{cc}
\left(\mathrm{d} / \mathrm{dt}+R_{i} / L_{q}\right) / L_{d} & \omega_{e} / L_{d} \\
-\omega_{e} / L_{q} & \left(\mathrm{~d} / \mathrm{dt}+R_{i} / L_{q}\right) / L_{q}
\end{array}\right]\left[\begin{array}{c}
i_{d s}^{e} \\
i_{q s}^{e}
\end{array}\right]
$$

Assuming a stable state in the machine (placing $p=0$ in Equation (2)), the equation between the currents can be rewritten as follows:

$$
\left[\begin{array}{l}
i_{d s}^{e} \\
i_{q s}^{e}
\end{array}\right]=\left[\begin{array}{cc}
1 & -\frac{\omega L_{q}}{R_{i}} \\
\frac{\omega L_{d}}{R_{i}} & 1
\end{array}\right]\left[\begin{array}{l}
i_{d T}^{e} \\
i_{q T}^{e}
\end{array}\right]
$$

As can be seen in the above equation, neglecting the iron losses $\left(R_{i}\right.$ unlimited), the current generating torque and stator current are equal, but it can also be seen that any non-unlimited value, $R_{i}$, leads to coupling between the currents and causes an angular displacement between the vectors of the terminal current and the torque current. This is depicted in Figure 2.

\section{q-axis}

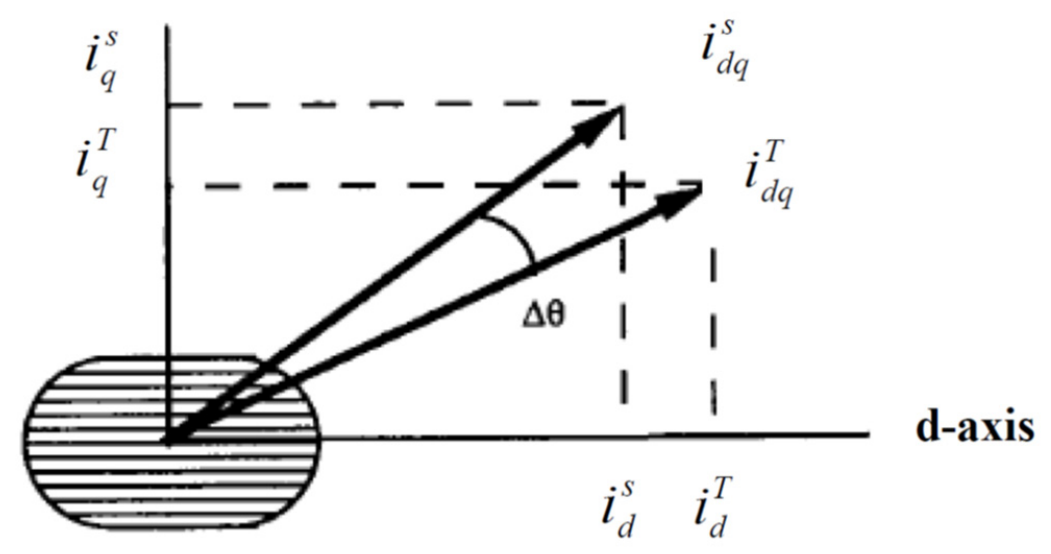

Figure 2. The relationship between torque current and terminal current vector, adopted from [34].

It can be seen that the lack of attention to the distinction between these two vectors causes a permanent error in torque, and the full realization of different strategies for controlling the torque of the reluctance synchronous motor, such as maximizing the efficiency (MEC) and controlling the maximum torque to the current (MTPA) and minimum inverter 
range KVA (Minimum Input KVA), is possible by compensating for coupling effects. The machine's voltage equations according to torque generator currents are:

$$
\left[\begin{array}{c}
v_{d s} \\
v_{q s}
\end{array}\right]=\left[\begin{array}{cc}
R_{s}+\mathrm{p} L_{d}^{\prime} & -\omega L_{q}^{\prime} \\
\omega L_{d}^{\prime} & R_{s}+\mathrm{p} L_{q}^{\prime}
\end{array}\right]\left[\begin{array}{c}
i_{d T}^{e} \\
i_{q T}^{e}
\end{array}\right] .
$$

where $L_{d}^{\prime}$ and $L_{d}^{\prime}$ are defined as follows. It is worth noting that these definitions are simply done in the rewrite of the equations and will not have any effect on the entirety of the problem.

$$
\begin{aligned}
& L_{d}^{\prime}=\left(1+\frac{R_{s}}{R_{i}}\right) L_{d} \\
& L_{q}^{\prime}=\left(1+\frac{R_{s}}{R_{i}}\right) L_{q}
\end{aligned}
$$

If the iron losses are ignored, $L_{d}^{\prime}$, and $L_{q}^{\prime}$, will be the same as $L_{d}$ and $L_{q}$. Additionally, the following useful equations can be used to calculate the torque generator currents in terms of stator voltages and currents. These equations are obtained using the KCL and KVL in Figure 1.

$$
\begin{aligned}
& i_{d}^{T}=\left(1+\frac{R_{s}}{R_{i}}\right) i_{d s}-\frac{v_{d s}}{R_{i}} \\
& i_{q}^{T}=\left(1+\frac{R_{s}}{R_{i}}\right) i_{q s}-\frac{v_{q s}}{R_{i}}
\end{aligned}
$$

The mechanical equations governing the system are as follows:

$$
\begin{gathered}
J_{m} \frac{\mathrm{d} \omega_{m}}{\mathrm{dt}}+B_{m} \omega_{m}=T_{e}-T_{l} . \\
\frac{d \theta_{m}}{d t}=\omega_{m}
\end{gathered}
$$

where $T_{l}$ is load torque, $T e$ is electrical torque, $\theta_{m}$ is rotor angular displacement, $\omega_{m}$ is rotor speed, $J_{m}$ is inertia moment, and $B_{m}$ is the viscosity coefficient.

By choosing $x_{1}=i_{d T}^{e}, x_{2}=i_{q T}^{e}$, and $x_{3}=\omega$ as state variables and $u_{1}=v_{d s}$ and $u_{2}=v_{q s}$ as inputs, the nonlinear dynamics of the reluctance synchronous motor by considering iron losses in the form of the standard state variable is:

$$
\begin{gathered}
\dot{X}=f(X)+g(X) U \\
X=\left[\begin{array}{lll}
x_{1} & x_{2} & x_{3}
\end{array}\right]^{T}, U=\left[\begin{array}{ll}
u_{1} & u_{2}
\end{array}\right]^{T}
\end{gathered}
$$

$$
f(x)=\left[\begin{array}{l}
f_{1} \\
f_{2} \\
f_{3}
\end{array}\right]=\left[\begin{array}{c}
-\frac{R_{S}}{L_{d}^{\prime}} x_{1}+\frac{L_{q}}{L_{d}} x_{2} x_{3} \\
-\frac{R_{S}}{L_{d}^{\prime}} x_{2}+\frac{L_{q}}{L_{d}} x_{1} x_{3} \\
\left(\frac{3 p\left(L_{d}-L_{q}\right)}{4 J_{m}} x_{1} x_{2}-\frac{T_{i}}{J_{m}}\right) / \frac{\mathrm{p}}{2}-\frac{B_{m} x_{3}}{J_{m}}
\end{array}\right], g(x)=\left[\begin{array}{ll}
g_{1} & g_{2}
\end{array}\right]=\left[\begin{array}{cc}
\frac{1}{L_{d}^{\prime}} & 0 \\
0 & \frac{1}{L_{d}^{\prime}} \\
0 & 0
\end{array}\right]
$$

\subsection{Strategy for Controlling Maximum Torque to Current}

Considering the iron losses, the main parameter to meet a particular control objective in the reluctance synchronous motor is the angle of the spatial vector of the torque currents relative to the rotor $\mathrm{d}$ axis. At this stage, a famous strategy for a reluctance synchronous motor (MTPA) is considered under the condition of producing a constant torque. In the strategy of maximum torque to current, minimizing stator current is selected as the target function. Based on the Lagrange theorem, it can easily be argued that the control strategy is realized when the torque curve and target function corresponding to that strategy are tangent at one point on each other or, in other words, the gradient vectors are parallel. 
As mentioned, this strategy can be achieved by minimizing the size of the stator current under the condition of constant torque at a given speed. The square size of the stator current of the synchronous motor is equal to:

$$
I_{s}^{2}=i_{d s}^{e^{2}}+i_{q s}^{e^{2}}=\left(i_{d T}^{e}+i_{d I}^{e}\right)^{2}+\left(i_{q T}^{e}+i_{q I}^{e}\right)^{2}
$$

where $i_{d I}^{e}$ and $i_{q I}^{e}$ are the currents associated with the iron losses, which can be calculated in the form below in constant mode.

$$
i_{d I}^{e}=-\omega_{e} \frac{L_{q}}{R_{i}} i_{q I}^{e}
$$

Therefore, the square of the stator current vector size can be expressed using Equations (15) and (16) in terms of torque currents (17).

$$
I_{s}^{2}=i_{d T}^{e^{2}}+i_{q T}^{e^{2}}+\frac{1}{R_{i}^{2}}\left(L_{d}^{2} i_{d T}^{e^{2}}+L_{q}^{2} i_{q T}^{e^{2}}\right) \omega_{e}^{2}+\frac{2}{R_{i}}\left(L_{d}-L_{q}\right) i_{d T}^{e} i_{q T}^{e} \omega_{e}
$$

At this stage, minimization (17) is considered as a target function under the condition of constant output torque production. As shown in Figure 3, the geometric location of the constant torque can be plotted as a hyperbolic on the plane of the torque biaxial currents. In addition, it can be shown that the geometric location of a constant stator current (either an active power of constant input or an appearance power of constant input) in the mentioned plane at a given speed forms part of an oval. The angle of its main axis increases with the axis $i_{q T}^{e}$ [25].

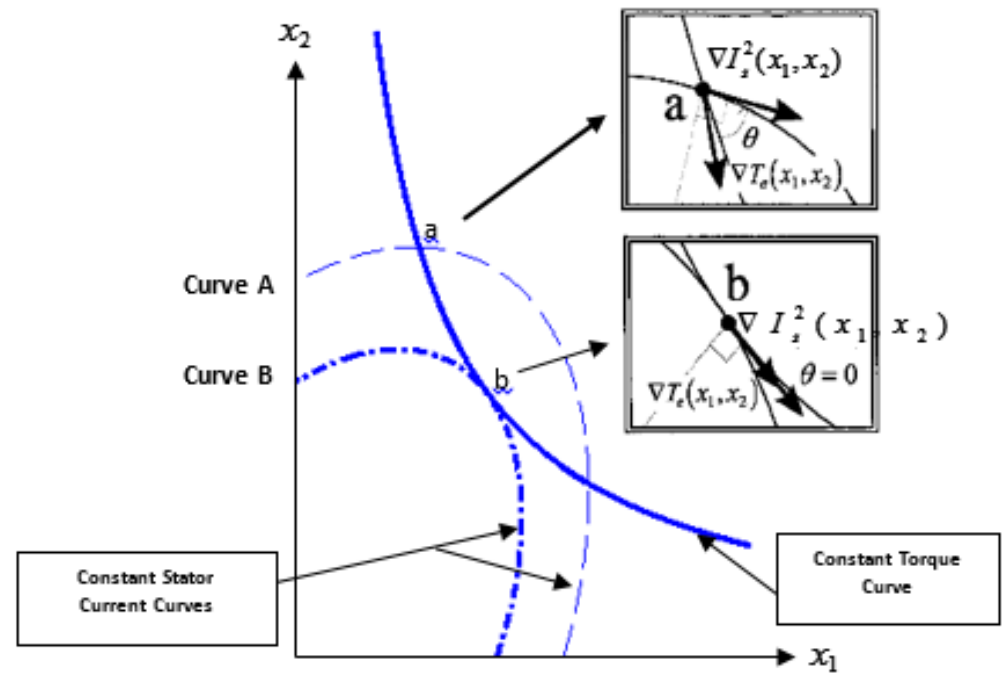

Figure 3. The geometric location of the constant torque and the constant stator current in the plane of biaxial currents of torque, adopted from [34].

Assuming that the torque is constant, if the working point is at point a, the stator constant current at this point is $I_{s a}^{2}$. If the work point is set at $\mathrm{b}$, then the stator's constant current will be $I_{s b}^{2}$. Using the Lagrange theorem, the stator current is minimized when the constant current curve and torque curve are tangent in a point, or in other words, if their gradient vectors are parallel, i.e., at a tangent point, and it should be possible to express $\nabla T_{e}\left(i_{d T}^{e}, i_{q T}^{e}\right)$ as a scalar coefficient $\nabla I_{s}^{2}\left(i_{d T}^{e}, i_{q T}^{e}\right)$ (point b). According to the above description, the following equation, which is in fact the external multiplication 
of two gradient vectors, must be met to minimize the objective function and realize the corresponding strategy in which $\theta$ is the angle between $\nabla T_{e}\left(i_{d T}^{e}, i_{q T}^{e}\right)$ and $\nabla\left(I_{s}^{2}, P_{i n}, S_{i n}\right)$.

$$
\left\|\nabla T_{e}\left(x_{1}, x_{2}\right)\right\|\left\|\nabla I_{s}^{2}\left(x_{1}, x_{2}\right)\right\| \sin \theta=0 \cdots \text { in MTPA }
$$

The criterion of realizing a strategy for controlling the maximum torque to current is:

$$
\begin{gathered}
\left\|\nabla T_{e}\left(i_{d T}^{e}, i_{q T}^{e}\right)\right\|\left\|\nabla I_{s}^{2}\left(i_{d T}^{e}, i_{q T}^{e}\right)\right\| \sin \theta=2 K_{T}\left[\left(1+\frac{L_{q}^{2}}{R_{i}^{2}} \omega_{e}^{2}\right) i_{q T}^{e}{ }^{2}-\left(1+\frac{L_{d}^{2}}{R_{i}^{2}} \omega_{e}^{2}\right) i_{d T}^{e}{ }^{2}\right]=0 \\
\Rightarrow i_{q T}^{e}= \pm i_{d T}^{e} \cdot \sqrt{\frac{\left(1+\frac{L_{d}^{2}}{R_{i}^{2}} \omega_{e}^{2}\right)}{\left(1+\frac{L_{q}^{2}}{R_{i}^{2}} \omega_{e}^{2}\right)}}
\end{gathered}
$$

If ohm losses are not considered $\left(R_{i}=\infty\right)$, the criterion for establishing the strategy of maximum torque is obtained in the ideal reluctance synchronous machine. In this case, the torque currents are the same as the terminal currents.

$$
i_{q T}^{e}= \pm i_{d T}^{e} \& i_{q s}^{e}= \pm i_{d s}^{e} \Rightarrow \varepsilon=\tan ^{-1}\left(\frac{i_{q s}}{i_{d s}}\right)= \pm 45^{\circ}
$$

However, in ideal mode, the optimum current angle is constant, but in real mode its value depends on the speed of the machine. However, the optimum current angle is larger than the ideal value in real mode.

\section{Intelligent Controller Based on Brain Emotional Learning}

Despite versatility and training, AI controllers require very strong computing in many practical applications to overcome the complexity and limitations of the system, and this requires more memory and more time to process and control. It should also be noted that many control issues can be carried out by other methods, but the advantage of the emotional method is that several complex issues can be solved by a strong computing process. Additionally, the emotional learning-based controller is the best choice for nonlinear systems due to its flexible structure [18]. The most important goal of this section is to use a structural model for timely selection and reactions based on a limbic system of the mammalian brain and emotional learning for decision making and engineering control applications. The proposed synthetic system takes inspiration from the natural processes in the biological system associated with the emotional process of the brain in order to receive sensory signals as a measure of system performance evaluation and output command signal generation. Therefore, it can qualitatively and quantitatively evaluate the system according to its predetermined goals and ultimately produce an output signal to improve its performance. In this section, the control system is considered as a general scheme, and the signals are presented parametrically in the form of mathematical equations so that the process integrity can be extended to any other system, and in particular, the equations can be used directly to develop the proposed control model in the later section. Figure 4 illustrates an image of the human brain, and Figure 5 shows the modified sensory signals and a communication model related to the learning network inside the brain [14]. As shown in Figure 5, the amygdala output is a combination of the inhibitory and excitatory signal data. The inhibitory signals $\left(\mathrm{O}_{1}, \mathrm{O}_{2}\right.$, and $\left.\mathrm{O}_{3}\right)$ come from the orbitofrontal cortex. The thalamus section processes sensory inputs, and its outputs are sent to the sensory cortex. Additionally, $\mathrm{V}_{1}, \mathrm{~V}_{2}$, and $\mathrm{V}_{3}$ from the amygdala are the other inputs of the sensory cortex. The outputs of the sensory cortex are sent to the orbitofrontal cortex. 


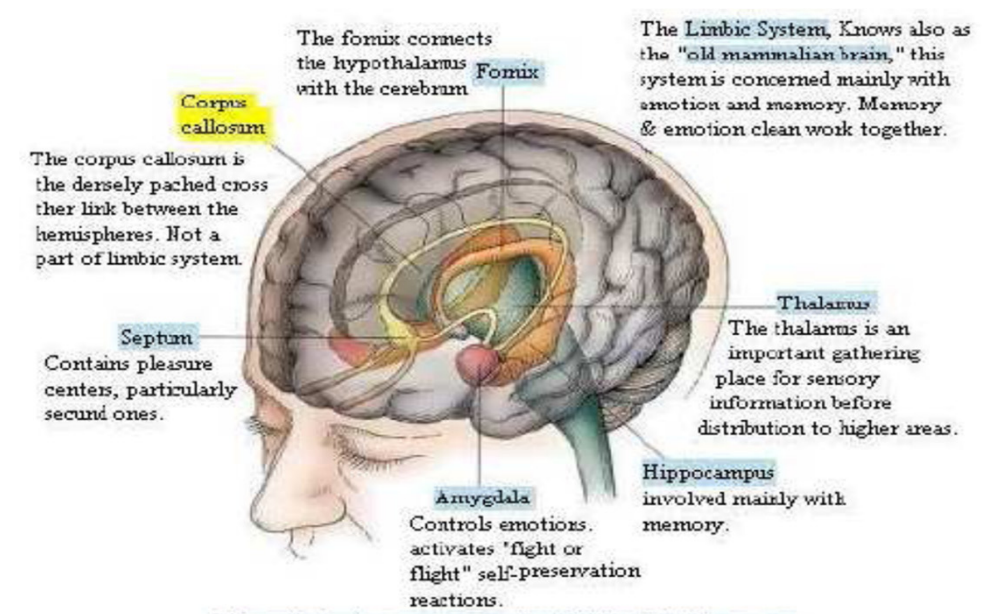

The major brain structures associated with the limbic system

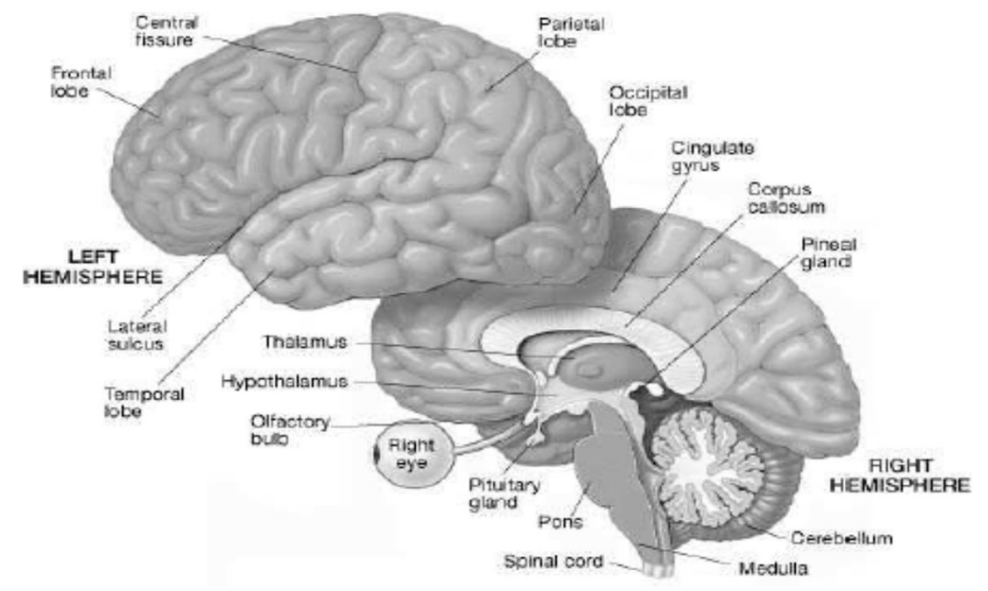

Figure 4. Brain structural related to the Limbic System, adopted from [22].

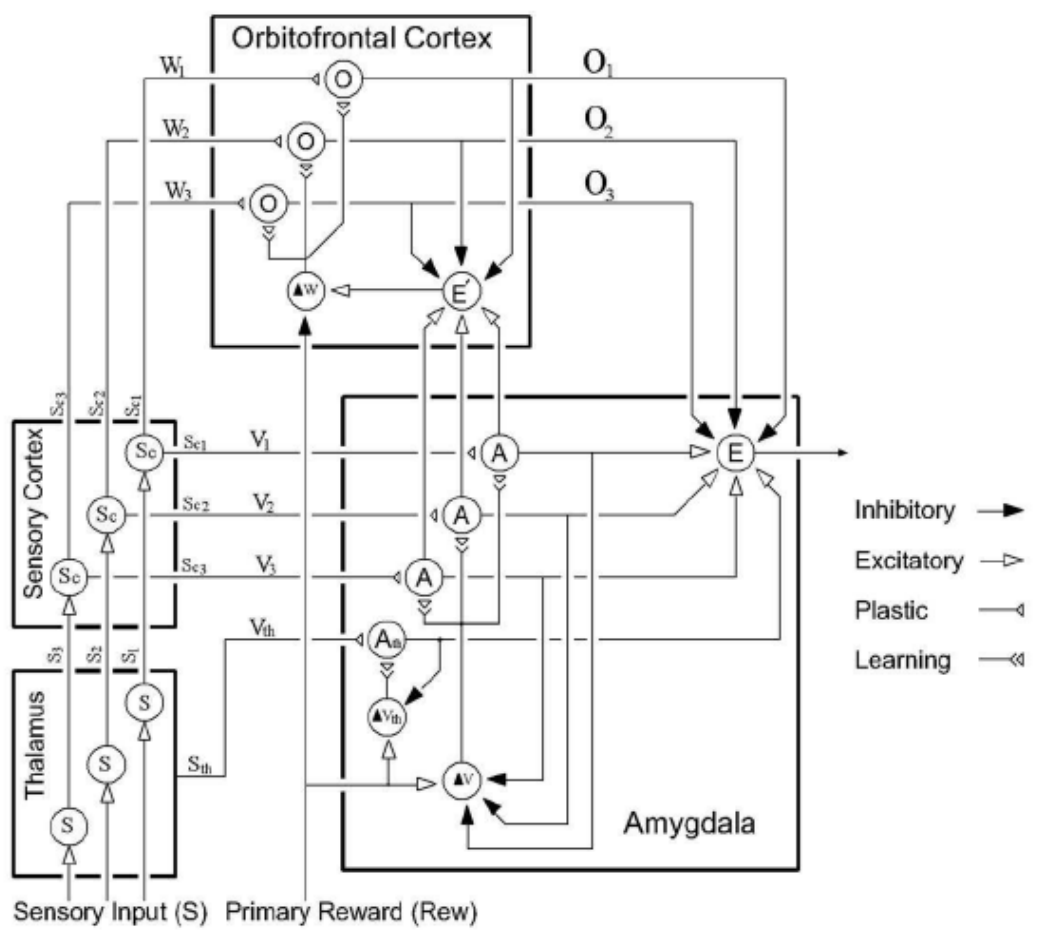

Figure 5. Graphical design of single-layer emotional controller, adopted from [22]. 


\section{Model of Emotional Controller}

The model studies of the BELBIC structure is graphically depicted in Figure 6. The BELBIC technique is essentially an active production mechanism based on sensory inputs and emotional cues. The selection of sensory inputs (feedback signals) depends on the type of process under control. In general, these inputs can be assumed as vectors. In order to display these vectors, sensory inputs and emotional signals (stress) have been investigated in [22]. In Figure 6, different nodes are used in place of the model, each of which is modeled with the same mathematical equations. An abstract of the structure of the limbic computing model of some parts of the mammalian brain is shown in Figure 7.

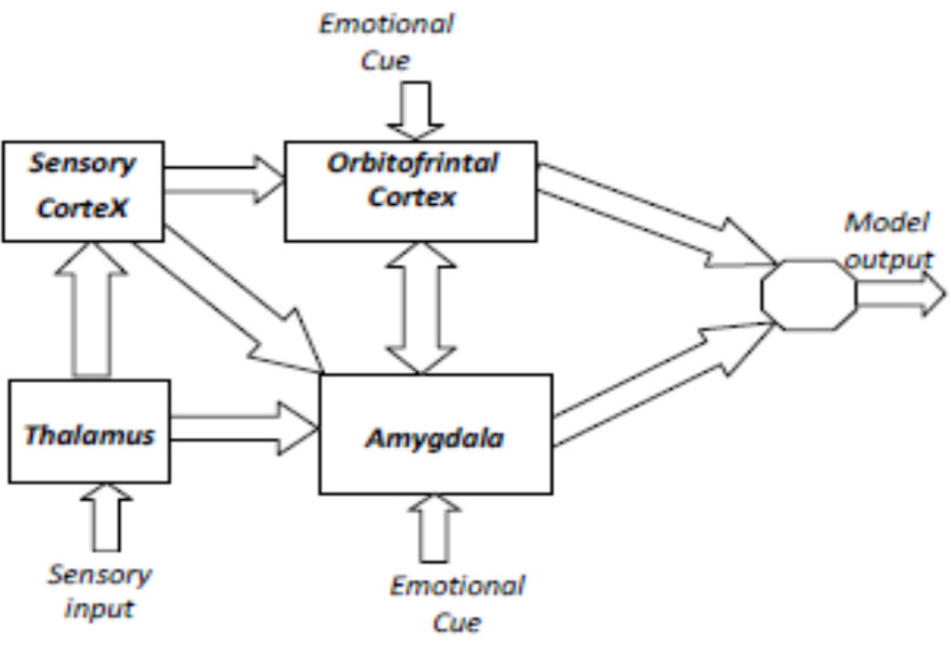

Figure 6. A graphical scheme of the single-layer emotional controller, adopted from [22].

By entering the sensory input and the emotional signal and processing them, the result is the output calculation from the model. In other words, E is obtained from Equation (22):

$$
E=\sum_{j} A_{j}+A_{t h}-\sum_{j} O_{j}
$$

The output sof the internal regions are obtained according to Equations (23) and (24), in which $A_{j}$ and $A_{t h}$ are the outputs of the Amygdala block and $O j$ is the output of the orbitofrontal. In the amygdala, there is a node for the input of the thalamus; the amount of this input is equal to the maximum sensory inputs:

$$
\begin{gathered}
A_{t h}=V_{t h} \cdot\left\{\max \left(S_{j}\right)=S_{t h}\right\} \\
A_{j}=S_{j} V_{j} \& O_{j}=S_{j} W_{j}
\end{gathered}
$$

In general, emotional learning occurs more in the amygdala; the amygdala learning rules are presented in (25) and (26), and as can be seen, the values of A cannot be reduced, i.e., the forgetting of information learned in the amygdala does not take place; in fact, "forgetting" or "deterrence" is the duty of the orbitofrontal cortex. In Equations (27) and (28), $S c_{j}$ is the sensory output and $\mathrm{j}$ is the index. Changes $V_{j}$ and $W_{j}$ are calculated according to (25) and (28), respectively:

$$
\begin{aligned}
& \Delta V_{j}=\alpha\left(\max \left(0, S c_{j}\left(R-\sum_{j} A_{j}\right)\right)\right) \\
& \Delta V_{t h}=\alpha_{t h}\left(\max \left(0, S_{t h}\left(R-A_{t h}\right)\right)\right)
\end{aligned}
$$




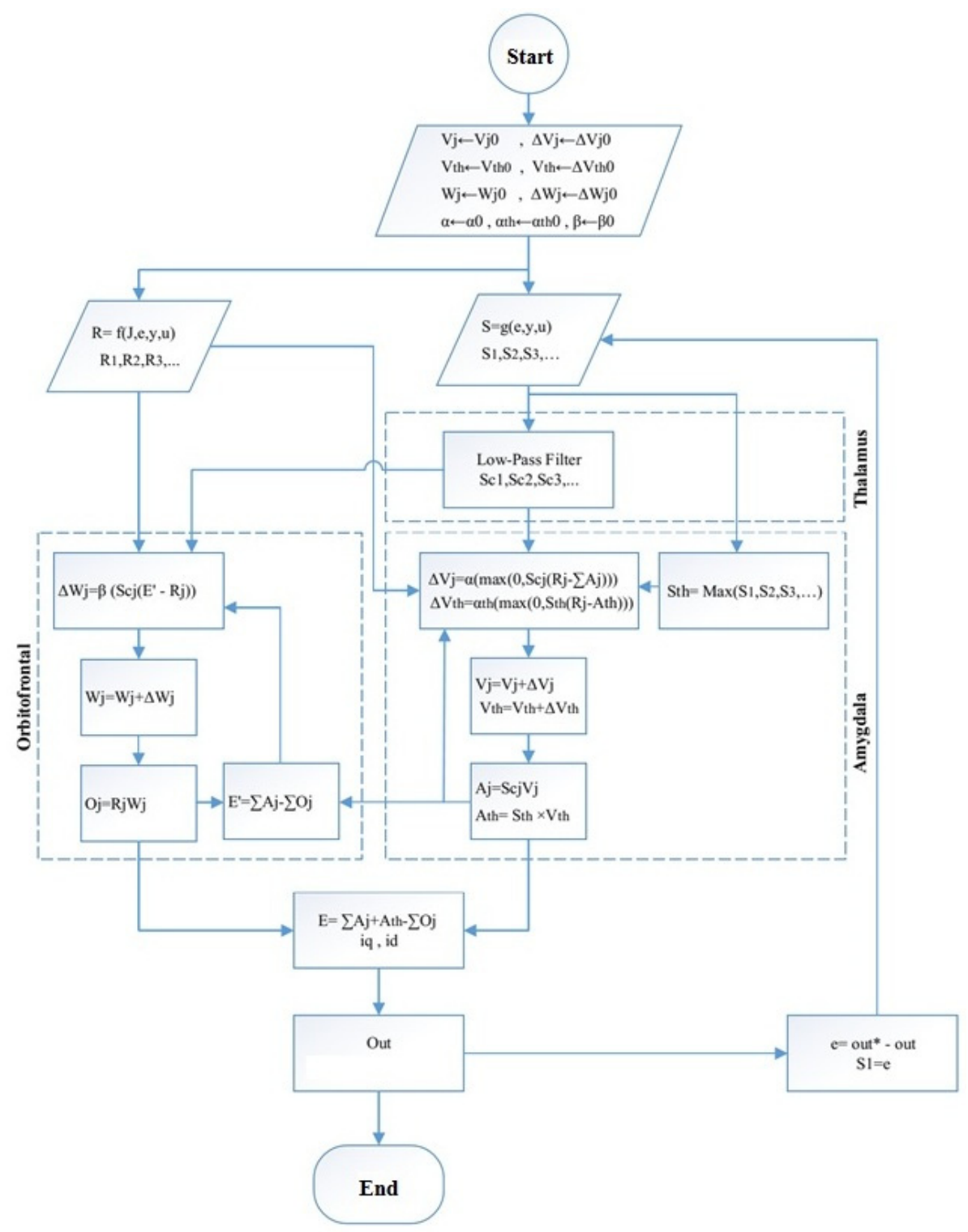

Figure 7. Flowchart and algorithm of emotional control system function.

The node $E^{\prime}$ is a collection of A outputs other than $A_{t h}$; after subtracting it from the inhibitory outputs, node $\mathrm{O}$ is obtained:

$$
\begin{gathered}
E \prime=\sum_{j} A_{j}-\sum_{j} O_{j} \\
\Delta W_{j}=\beta\left(S c_{j}(E \prime-R)\right)
\end{gathered}
$$

where $\alpha$ and $\alpha_{t h}, \beta$ are the learning steps in the amygdala and orbitofrontal, respectively. Additionally, $R$ is the emotional sign function and $S$ is the emotional signal, which are calculated by Equation (29):

$$
R=f(J, e, y, u), \quad S=g(e, y, u)
$$

where, $e, u, y$, and $J$, respectively, are system error, controller output, system output, and desired target function. In any case, the initial values for $\alpha$ and $\beta$ in $O$ and $A$, and functions $\mathrm{R}$ and $\mathrm{S}$ for generating emotional signals, must be selected. Here, the functions $\mathrm{g}$ and $\mathrm{f}$ are 
defined according to Equation (30) and can be defined according to the control need of the user:

$$
g=k_{1} e+k_{2} \frac{d}{d t} e+k_{3} \int e d t, f=K_{1}|e|+K_{2}|e y|+K_{3}\left|y_{P}\right|
$$

where $e$ is system error, $y_{p}$ is controller output, and $y$ is system output, and coefficients $K$ and $k$ must be considered in a proper manner. The use of the equations tilted emotional controller and its general implementation in the control systems are shown in Figure 8.

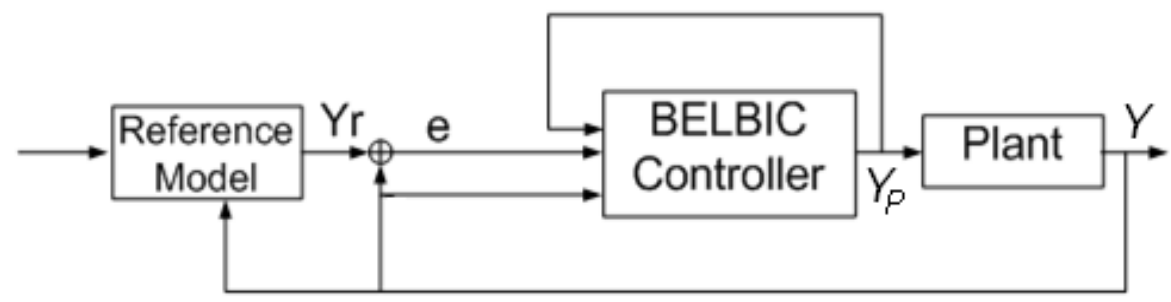

Figure 8. General outline of the emotional controller function, adopted from [22].

According to what has been said regarding the emotional controller structure, functional characteristics such as adaptability and automated learning can be seen in a simple structure. Therefore, as a high-performance controller, a suitable option for controlling the reluctance synchronous motor drive can be proposed. A noteworthy point in this controller's settings is the design of the emotional signal and the amplification signal (stress). The user can achieve their control goals through the proper design of these functions. To design this control system, the initial setup, if it is only placed in a stable area, will operate to improve its performance after executing at each stage of the system through its training process. Initial settings are made through trial and error.

\section{Vector Control of the Drive Speed of the Reluctance Synchronous Motor with the Implementation of Maximum Torque per Ampere Strategy}

According to the studies in the previous sections, designing proper control for electric drives, in particular the magnetic synchronous motor, has continually been investigated, and various solutions have been proposed. Sophisticated nonlinear methods as well as fuzzy-based methods seek higher control performance in the system. Conventional PID controllers, despite their problems, are still preferable to their new rivals in the industry. PID controllers have simple structures, and they are suitable for controlling systems. One of the main problems of this group of controllers are challenging issues such as proper adjustment of the coefficients, as well as changes in the quality of their performance. Adjustment of their coefficients is mainly carried out through a trial-and-error method, which is time-consuming and not accurate enough. Of course, in recent years, with the introduction of evolutionary and biological optimization methods such as genetic algorithms, this problem has been studied through the application of these optimization algorithms. The results presented in various papers have indicated the improvement of system performance. However, the issue of changing the quality of performance of PID-based control systems persists, especially when we want to use them in a wide range of workplace variations; even when based on the structure of the drives, we will see changes in machine parameters due to the effects of saturation. Therefore, the design of an advanced drive system requires a proper control structure that also has proper functions in a wide range of work and parameter variations, and, in practice, has a simple structure for execution in a practical environment.

Through advancements in intelligent controllers, more advanced methods have been presented to improve the controlling performance by maintaining the simplicity of the implementation. Control systems based on emotional processes include these advanced controllers, which have attracted a lot of attention recently. This intelligent control system, despite the simplicity of the structure, has adaptive characteristics and independence from changes in plant parameters and work points. The controller, first presented by 
Professor Caro Deluxe and his research team in 2002, has been used as a competitive point with other controllers over the years. This new control system, which works based on emotional systems, has shown its superiority in comparison with many of the common control systems. Accordingly, in this paper, this intelligent control is studied based on the proper design of the controllers of speed and flux of reluctance synchronous motor drives.

The second topic included in this section is the storage and power reduction strategies that have been discussed with regard to the current energy crisis. Electric drives that allocated about $30 \%$ of the power consumed certainly have a special position within this topic. In this regard, the maximum torque per ampere strategy can be an appropriate response to this problem. Therefore, a proposed drive performance based on this power optimization strategy is presented. The network's $(400 \mathrm{~V}, 50 \mathrm{~Hz})$ single-line diagram is shown in Figure 9.

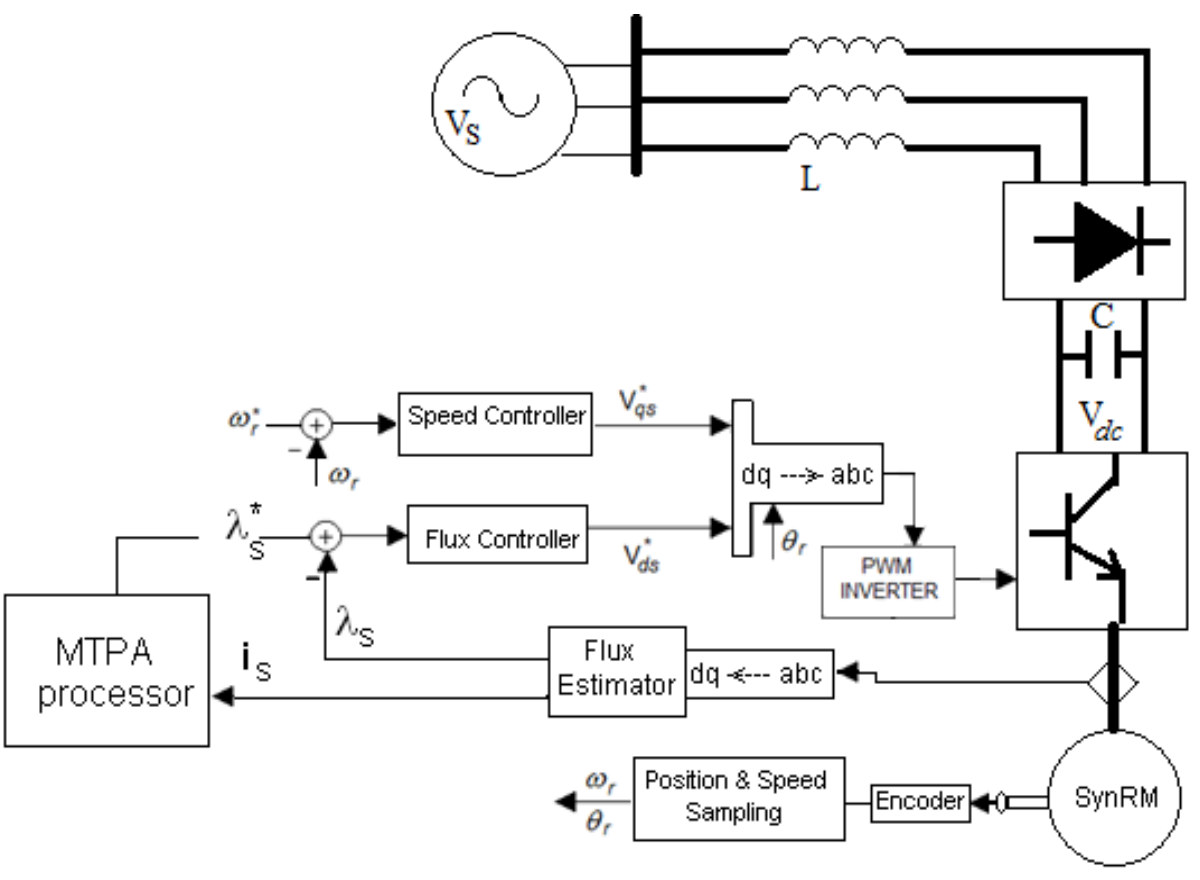

Figure 9. Single-Line Diagram of the Network.

\subsection{Proposed Scheme of a Permanent Magnet Synchronous Motor Drive}

The proposed scheme is presented in Figure 9. In this scheme, which is in the rotor rotary device, after sampling voltage and stator phase current, the value of the stator magnetic flux is estimated, and the rotor speed is read through an encoder. Finally, each of the values of the magnetic flux and the measured velocity are compared with their reference values, each of them entered separately into the speed controller and the flux controller. This structure, which is based on vector control, as the vertical axis of the device responsible for generating the electromagnetic torque and as a result of the speed controller output, produces the components of the vertical axis and the voltage. Additionally, the magnetic flux controller produces a component voltage in line with the rotary axis to feed the reactive power associated with the flux.

In the proposed scheme of SynRM drive control, BELBIC's emotional controllers are used. As discussed in detail in the previous section regarding this new type of intelligent control systems, two important input signals called emotional and reinforcement signals (stress) should be designed based on the control objectives. In the proposed model, Figure 9 , there are two independent controllers for the rotor speed and magnetic flux. For each controller, the parameters of the control signal, control signal error, and the plant output signal, as in Figure 8, can be assigned. The general purpose of designing these controllers here is generally to reduce the error and integrate it, which, of course, tends to maintain 
the response dynamics described in the next section in relation to the definition of these control input functions.

\subsection{Designing the Emotional Proposal Controller}

The BELBIC emotional controller, discussed in detail in the previous section, is one of the most innovative biological inspired system algorithms. In the proposed drive structure, as mentioned above, there are two rotor speed controls and a magnetic flux control, which is proposed as follows for each of these input function controllers. It should be mentioned that the closer the signal of error reaches zero, the better the performance will be. Of course, the most important factor is that the controller dynamic response should be in accordance with accepted dynamic systems. In other words, if the control signal has a size limitation for applying the system under control, then the controller must also be designed to comply with this limitation. For example, in the proposed speed controller, the control signal is a vector of the vertical axis of the stator; therefore, its value should not exceed the motor's nominal value.

First, for the speed controller, we present the corresponding signals according to Equations (29) and (30), and control objectives:

$$
g=k_{1} \Delta \omega_{r}+k_{2} \frac{d}{d t} \Delta \omega_{r}+k_{3} \int \Delta \omega_{r} d t, f=K_{1}\left|\Delta \omega_{r}\right|+K_{2}\left|\Delta \omega_{r} \cdot v_{q}\right|+K_{3}\left|\omega_{r}\right|
$$

Here, $\Delta \omega_{r}$ and $v_{q}$, respectively, are the rotor speed error and the emotional control output. Function $\mathrm{f}$ is known as the amplifier signal and is defined as a control criterion for the system. The coefficients $K$ and $\mathrm{k}$ are also constant coefficients that are specified by the user. As it can be seen, the amplifier function has components of the output signals, $v_{q}$, and the output signal of the system, $\omega_{r}$, completely non-linear so that it can be restricted by the value of this controlling parameter of voltage, $v_{q}$, by regulating coefficient $K_{2}$. In relation to the flux controller magnetic flux error, $\Delta \lambda_{s}$, the output signal, $v_{q}$, is used in accordance with the following equations:

$$
g_{2}=k_{1}^{\prime} \Delta \lambda_{s}+k_{3}^{\prime} \int \Delta \lambda_{S} d t, f_{2}=K_{1}^{\prime}\left|\Delta \lambda_{S}\right|+K_{2}^{\prime}\left|\Delta \lambda_{S} \cdot v_{d}\right|+K_{3}^{\prime}\left|\lambda_{S}\right|
$$

\section{Results of Proposed Drive Implementation in Simulation}

\subsection{Results of Simulation of Flux Control and Speed of SynRM Drive}

To investigate the proposed scheme, two tests are performed using the MATLAB simulator software under different operating conditions. In the first test, the command is given at a speed of $500 \mathrm{rpm}$ at the start and, at $0.9 \mathrm{~s}$, a speed command is applied to the speed control with an amount of $750 \mathrm{rpm}$. Additionally, a constant flux command with a value of $0.8 \mathrm{~Wb}$ is initially applied to the system, and at $0.4 \mathrm{~s}$, its value is changed to $0.7 \mathrm{~Wb}$. This test is performed using two BELBIC and PI conventional emotional controllers. It should be noted that the conventional controller is set based on the conventional genetic algorithm (PICon) [35]. The comparison of speed and flux control using BELBIC and the conventional PI controller set with GA is shown in Figure 10. Figure 10(a1) shows rotor speed, and Figure 10(a2) shows rotor angular velocity. As shown in Figure 10(a1), both controllers have an appropriate response speed, but the PICon-based control system has a significant increase compared to controllers based on the emotional controller. On the other hand, the time of the proposed scheme based on the emotional controller is much shorter. In addition, on the side of the magnetic flux controller, this superiority of BELBICbased controllers is clearly seen (Figure 11(b1)). Figure 11b illustrates that the PICom-based controller has less dynamics and a more significant ripple than the BELBIC-based controller. Additionally, the behavior of the stator current in Figure 12 can also show flow changes relative to flux variations. As can be seen, though the flux value was initially set at $0.8 \mathrm{~Wb}$, but with a decrease to $0.7 \mathrm{~Wb}$, the torque component adequately performs the speed control 
process; this means that it can be used for low torque axis and current and electrical power by adjusting the magnetic flux at any point and maintaining the function.

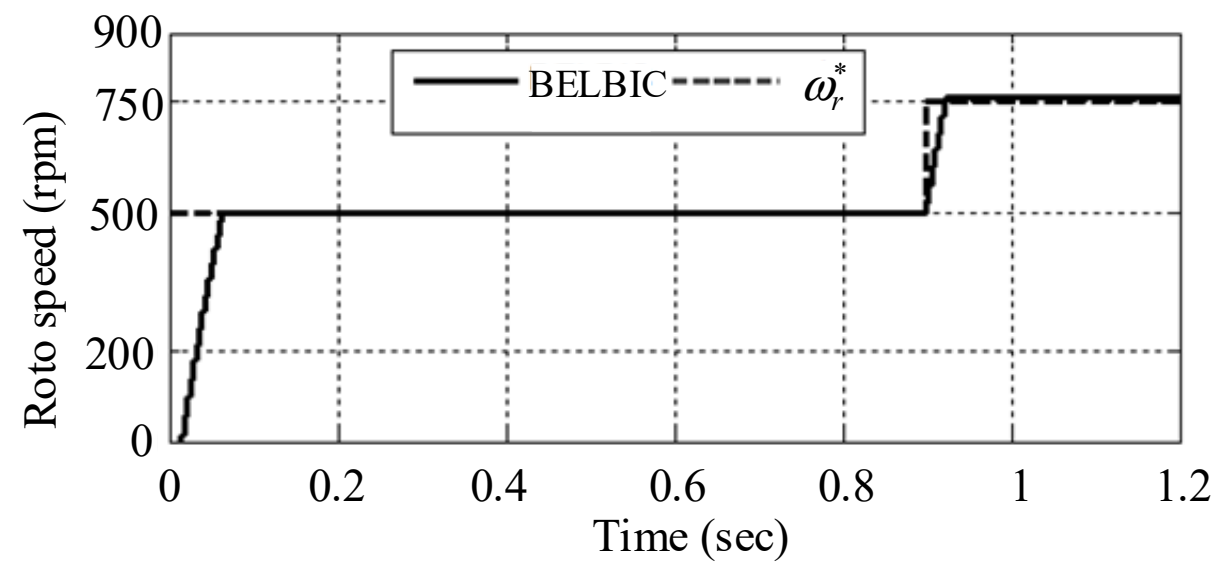

(a1)

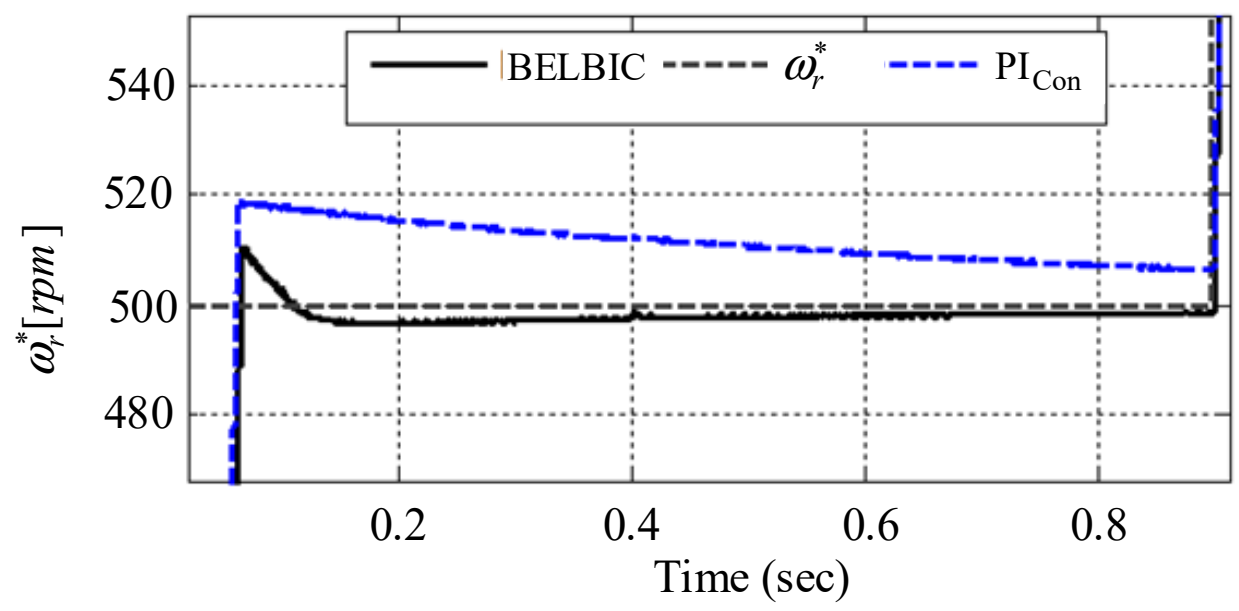

(a2)

Figure 10. Speed and flux control using BELBIC and the conventional PI controller set with GA. (a1) Rotor speed, (a2) Rotor angular velocity.

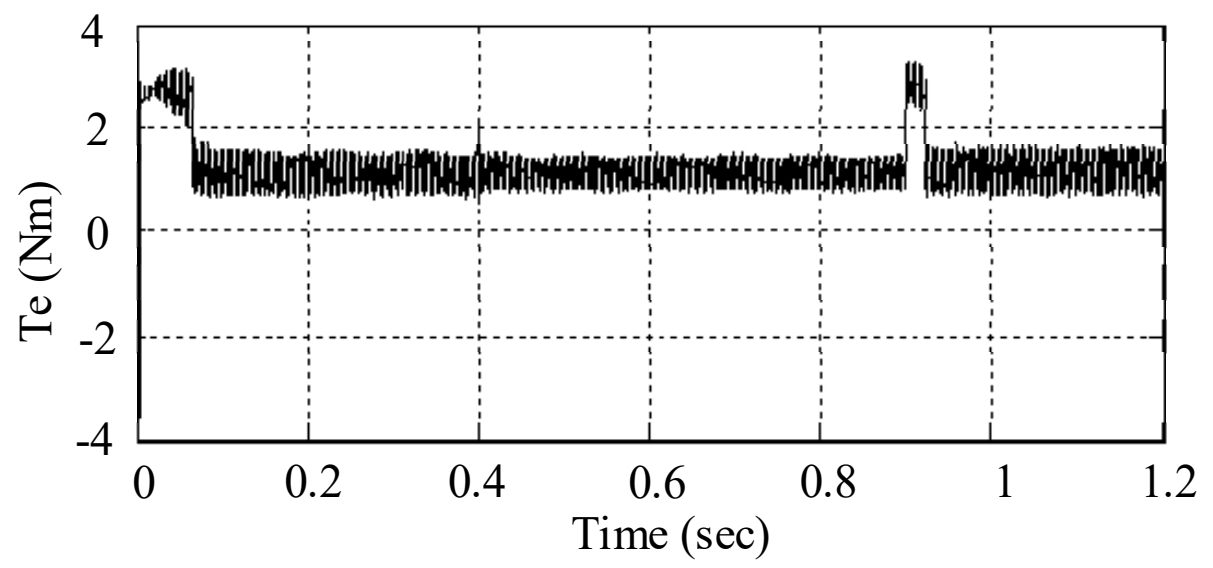

(a)

Figure 11. Cont. 


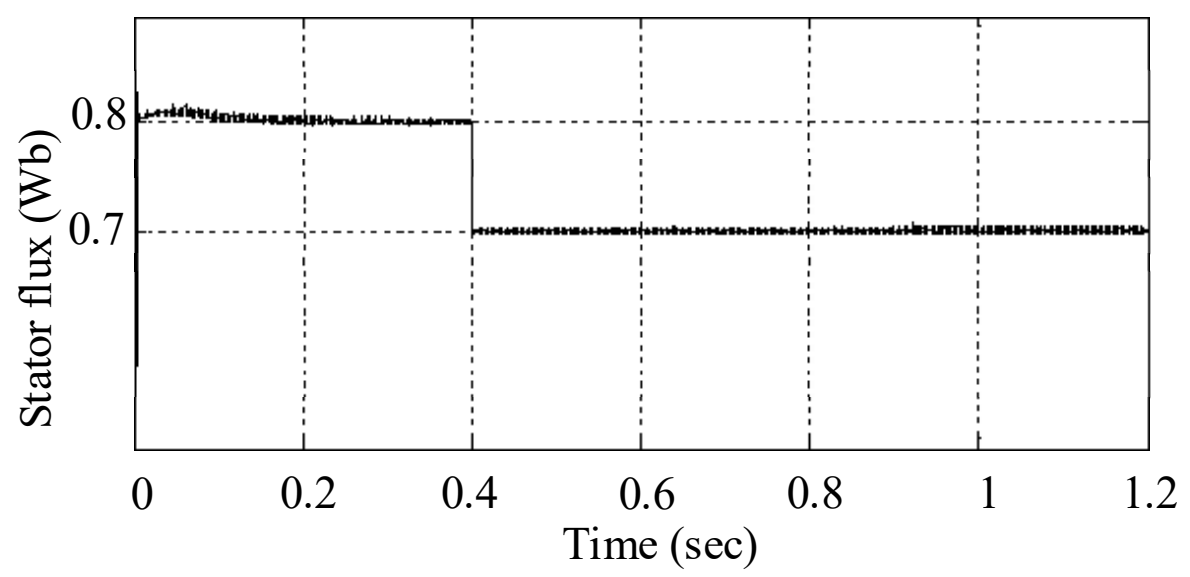

(b1)

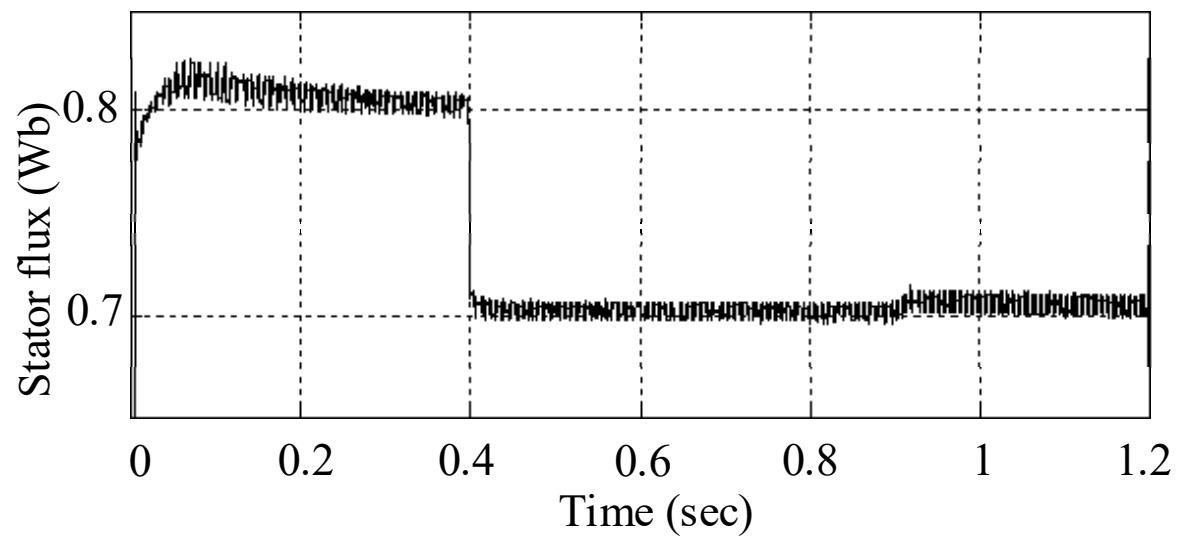

(b2)

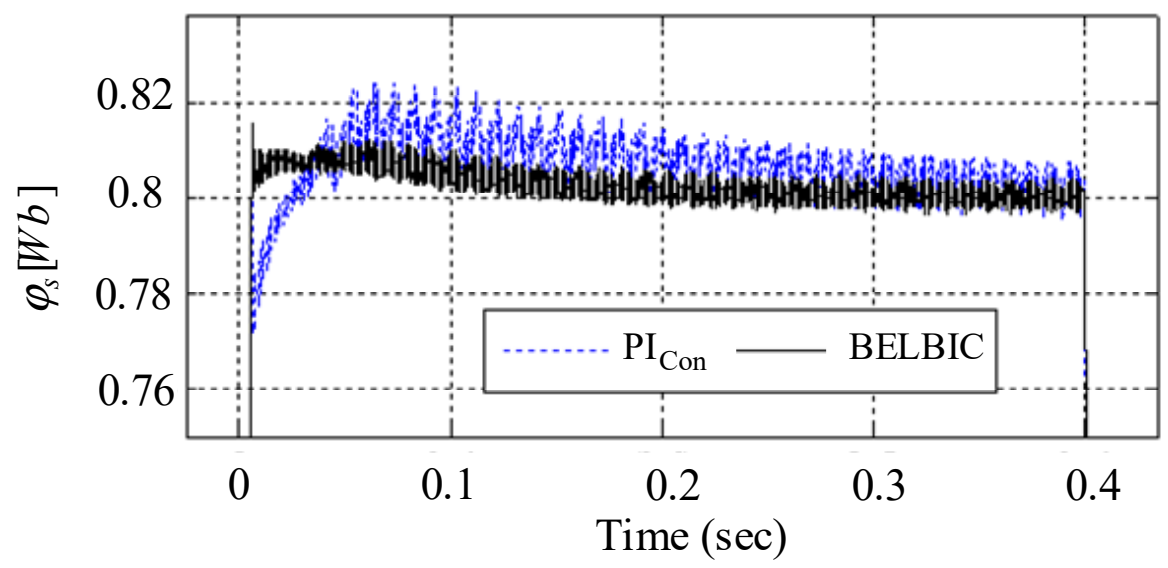

(b3)

Figure 11. Control of velocity and flux using BELBIC and the conventional PI controller regulated by GA. (a) BELBIC electromagnetic torque, (b1) the magnetic flux of the stator, (b2) using the proposed method, (b3) the conventional method [36]. 


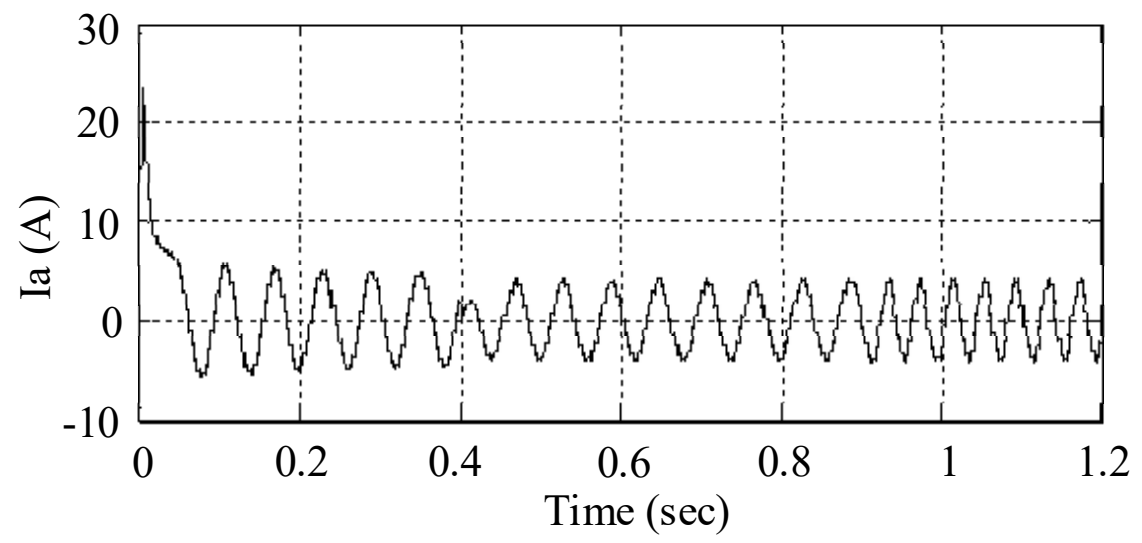

(a)

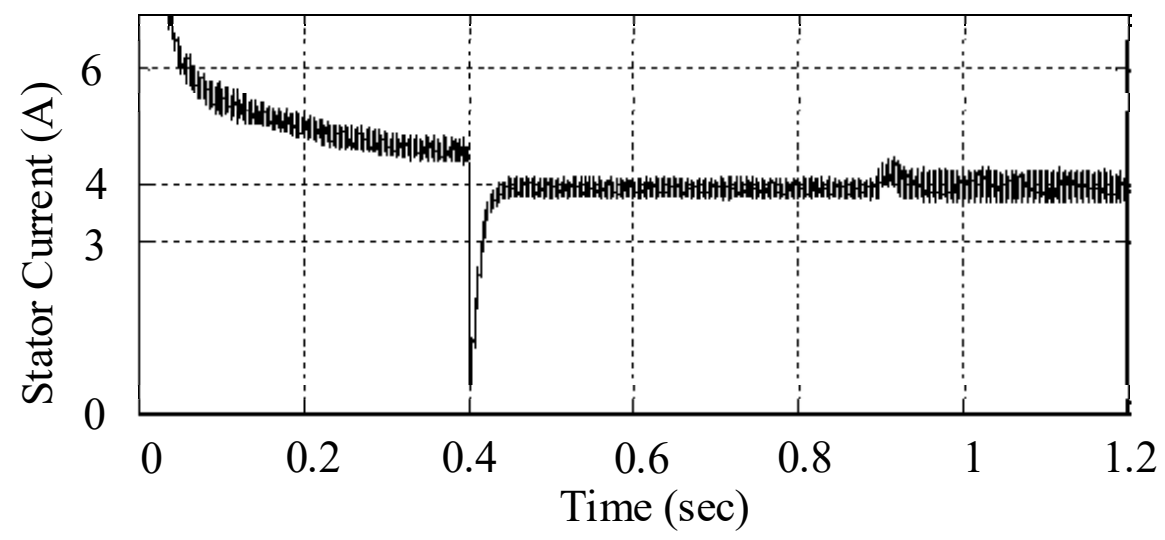

(b)

Figure 12. Speed and flux control using BELBIC. (a) Stator phase current, (b) current vector of total stator.

\subsection{Results of Simulation of MTPA Strategy in the Drive of a Reluctance Synchronous Motor}

This issue in the second experiment implemented under the MTPA strategy. The second experiment, in fact, replicates the speed control of the first experiment, but under the strategy of optimizing the stator flux. As shown in Figure 13, the speed control has followed its reference value well. As in the first step of the command, after less than $0.1 \mathrm{~s}$, the reference value is $500 \mathrm{rpm}$, and at $0.7 \mathrm{~s}$ the speed command is $1000 \mathrm{rpm}$; the controller has followed the value of reference well while maintaining the acceptable performance quality in certain aspects: a constant zero error, without rising or falling speed. For the second aspect of the work, which is the simultaneous implementation of the MTPA strategy, if Figure 14a is paid attention to, flux reference variations are modified in accordance with the MTPA search pattern. Initially, the motor receives $0.5 \mathrm{wb}$ of maximum flux for its upper dynamics. After passing through the transition conditions and reaching the stable state in $0.1 \mathrm{~s}$, using the search for the maximum torque point on ampere MTPA, the flux can be reduced. This decrease begins after the stability of the motor at steady state and ends with reaching the MTPA point. 


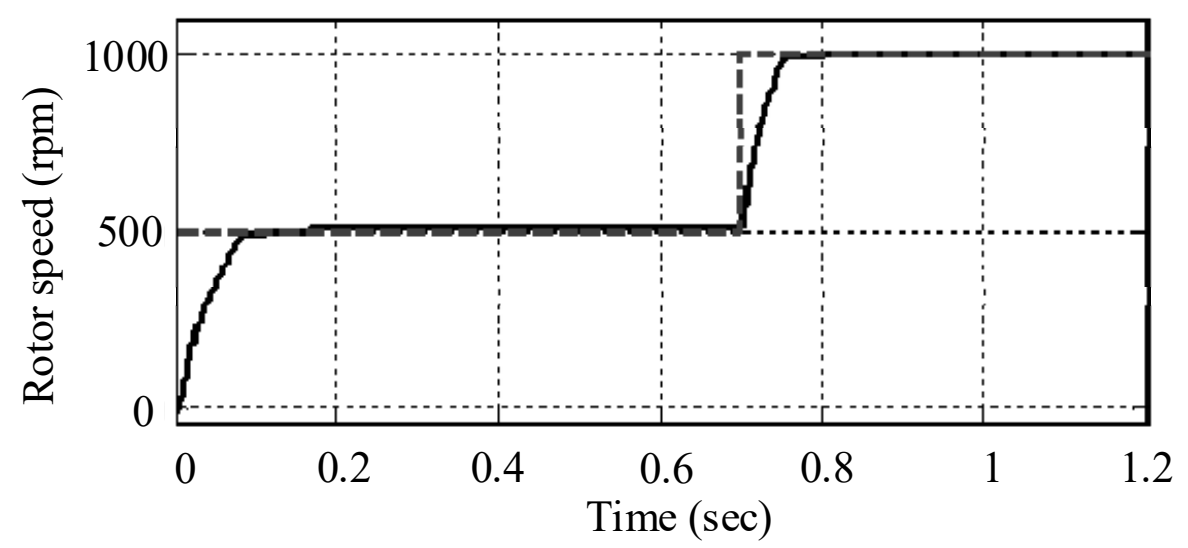

(a)

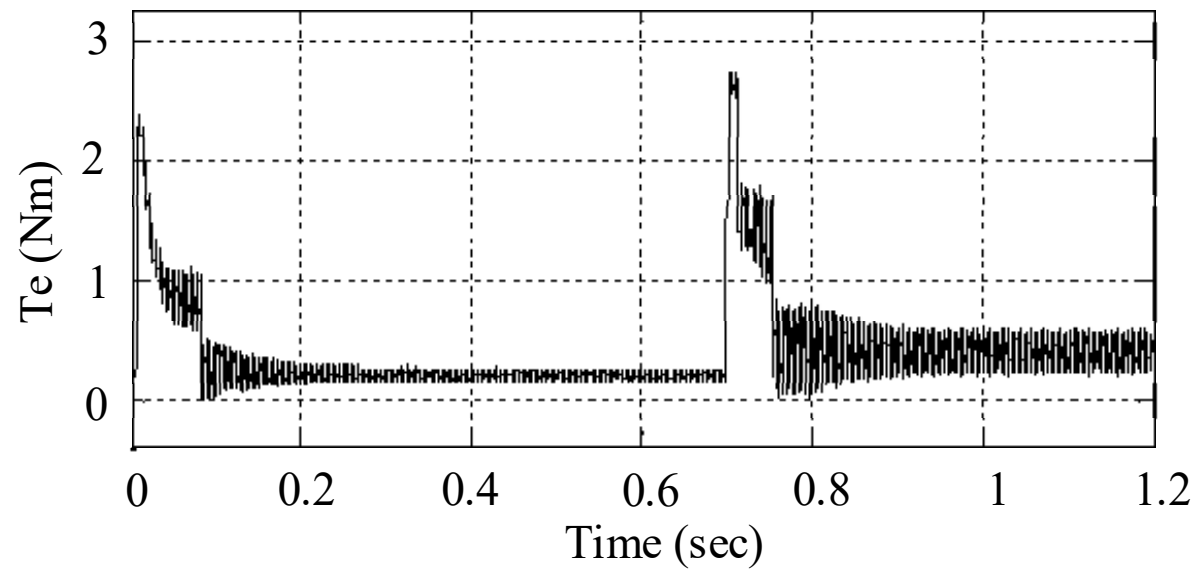

(b)

Figure 13. Results of optimal control under the MPTA strategy. (a) Rotor speed, (b) electromagnetic torque.

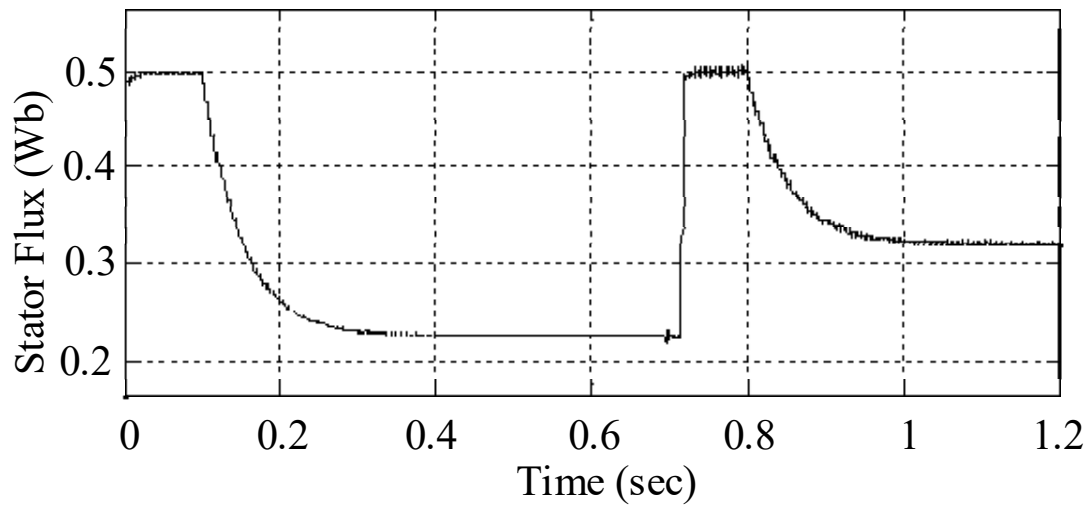

(a)

Figure 14. Cont. 


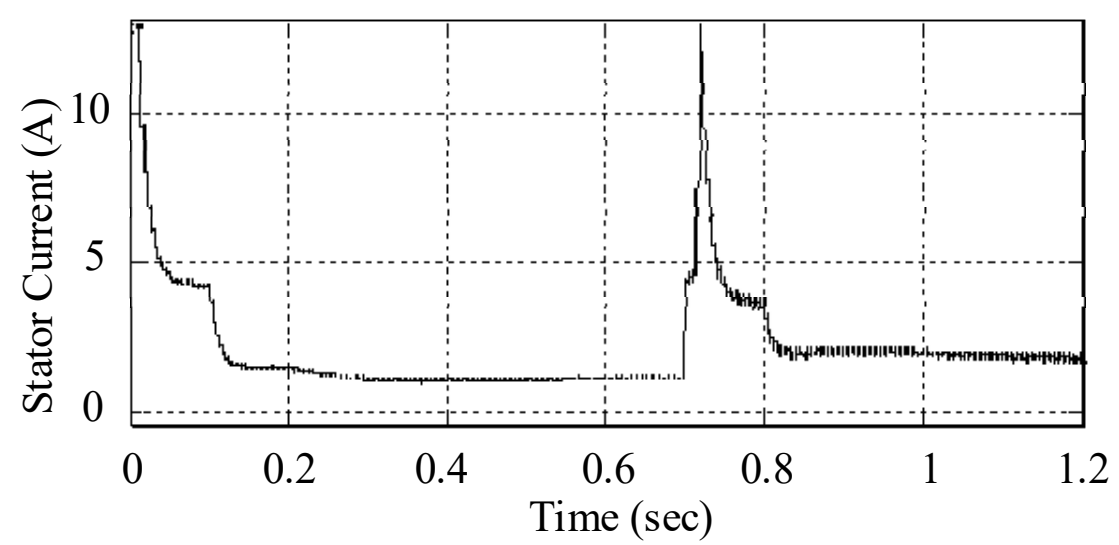

(b)

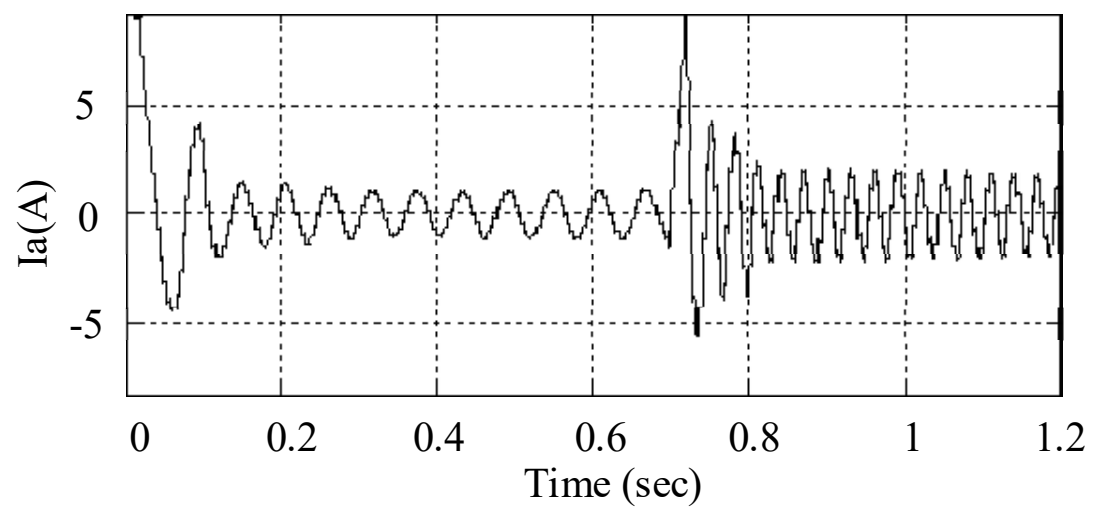

(c)

Figure 14. Results of optimal control under the MPTA strategy. (a) Magnetic flux, (b) Stator current size, (c) Stator phase current.

At each sampling stage of the current's signals, this momentary amount, which changes as a result of the momentary reduction, is compared with its previous value. Figure 14 shows results of optimal control under the MPTA strategy. Figure $14 \mathrm{a}-\mathrm{c}$ show magnetic flux, Stator current size and stator phase current respectively. As shown in Figure 14, the MTPA proposed algorithm with an exponential function reduces the reference flux, and this decrease continues so much that it has a decreasing total current size. In general, the MTPA strategy is at the point of minimum current changes relative to current changes. If the flux is reduced, in other words, the derivative of the flux changes is negative, and if the current changes are decreasing, in other words, the derivative of the flux changes is negative, this decrease of the reference flux is continued through MTPA, as long as the sign of changes of the flux is contrary to the sign of changes of the current (the derivative of the flux in the derivative of the current is eliminated). The border point between the changes of sign is called the MTPA point in those working conditions. Note that the MTPA point changes due to the change in the work point, which should then be searched for the point corresponding to the new working conditions by the procedure described.

In Table 1 , the qualitative comparison of several methods of controlling electrical drives can be observed. As shown, direct torque control, despite its high dynamics, suffers from high ripples as well as a non-constant switching frequency. Regarding the low RIPLL and its relatively good performance, the vector control method can also create challenges from the dependence of its controller structure on changing machine parameters as well as changes in the quality of response to the change to the point of work. Linear control methods, such as sliding mode, have a higher controlling effort in relation to the higher response and the constant switching frequency. In addition, due to the use of variable structure methods in some of its headings, it can severely show the system complex. 
Table 1. Comparison of the qualitative performance of the proposed scheme to proposed control structures in references.

\begin{tabular}{ccccccccc}
\hline Control Method & $\begin{array}{c}\text { Response } \\
\text { Dynamics }\end{array}$ & $\begin{array}{c}\text { Torque and } \\
\text { Flux Ripple }\end{array}$ & $\begin{array}{c}\text { Dependence } \\
\text { to Parameter }\end{array}$ & $\begin{array}{c}\text { Controlling } \\
\text { Effort }\end{array}$ & Complexity & $\begin{array}{c}\text { Switching } \\
\text { Frequency }\end{array}$ & $\begin{array}{c}\text { Resistance to } \\
\text { Change in } \\
\text { Work Point }\end{array}$ \\
\hline Proposed method & Good & Low & Low & Low & Low & Fix & High \\
\hline $\begin{array}{c}\text { Direct control of } \\
\text { torque [35] }\end{array}$ & High & High & Low & Relatively low & Low & Variable & High \\
\hline $\begin{array}{c}\text { Vector control } \\
\text { method [36] }\end{array}$ & Low & Low & High & Relatively low & $\begin{array}{c}\text { Relatively } \\
\text { low }\end{array}$ & Fix & Low \\
\hline $\begin{array}{c}\text { Sliding mode } \\
\text { method [37] }\end{array}$ & Good & High & High & High & High & Fix & Good \\
\hline
\end{tabular}

\section{Conclusions}

In this paper, an attempt was made to provide an appropriate scheme of performance for a control system based on the standard structure of an AC drive motor. Therefore, the structure based on vector control in a rotor rotary machine and using intelligent emotional controllers has been investigated. To use a PI controller in industry, the issue of adjusting and changing the quality of its performance has been challenged. Intelligent emotional control systems were proposed to replace this conventional system. This new type of intelligent control system has been able to show features such as adaptability, automatic learning, and independence of parameter changes by maintaining the simplicity of the structure and has ultimately led to the provision of a practical control function. The results obtained from the comparison of the proposed scheme and optimal conventional PI systems has indicated the improvement in the performance of these intelligent controllers compared to conventional methods; the stator flux peak in the proposed method is $1.25 \%$, and for the conventional method it reaches $2.625 \%$. The time at signal of speed is about 75 milliseconds, and is about 275 milliseconds in the conventional PI-based method. Another discussion in this paper, the issue of energy savings, is important, and the MTPA strategy is proposed for this. This strategy, based on the search for the minimum curvature of variations of the size of the current, changes the size of the magnetic flux. The proposed system has been studied in simulation. Comparing the performance of the proposed method with the direct control of torque, vector control, and sliding mode methods showed that the method used in this paper has a better performance than other methods. The proposed method has a good dynamic response, and its torque and flux ripples are less than other methods. The proposed low complexity method has low dependency on parameters, and its switching frequency is fixed.

Author Contributions: Conceptualization, M.A.K. and H.S.; methodology, M.A.K. and H.S.; software, M.A.K. and H.S.; validation, M.A.K. and H.S.; formal analysis, M.A.K. and H.S.; investigation, M.A.K. and H.S.; resources, M.A.K.; data curation, M.A.K., H.S., I.C. and K.E.; writing-original draft preparation, M.A.K. and H.S.; writing-review and editing, M.A.K., H.S., I.C. and K.E.; visualization, M.A.K., H.S., I.C. and K.E.; supervision, M.A.K., H.S., I.C. and K.E.; project administration, M.A.K., H.S., I.C. and K.E.; funding acquisition, M.A.K., H.S., I.C. and K.E. All authors have read and agreed to the published version of the manuscript.

Funding: This research received no external funding.

Conflicts of Interest: The authors declare no conflict of interests.

\section{References}

1. Takahashi, I.; Noguchi, T. A New Quick Response and High Efficiency Control Strategy of an Induction Motor. IEEE Trans. Ind. Appl. 1986, 22, 820-827. [CrossRef]

2. Asadi, M.; Shokouhandeh, H.; Rahmani, F.; Hamzehnia, S.M.; Harikandeh, M.N.; Lamouki, H.G.; Asghari, F. Optimal placement and sizing of capacitor banks in harmonic polluted distribution network. In Proceedings of the 2021 IEEE Texas Power and Energy Conference (TPEC), College Station, TX, USA, 4-5 February 2021; pp. 1-6.

3. Nash, J.N. Direct Torque Control, Induction Motor Vector Control without an Encoder. IEEE Trans. Ind. Appl. 1997, 33, 333-341. [CrossRef] 
4. Faiz, J.; Sharifian, M.B.B.; Keyhani, A.; Proca, A.B. Sensorless Direct Torque Control of Induction Motors used in Electrical Vehicle. IEEE Trans. Energy Convers. 2003, 18, 1-10. [CrossRef]

5. Titinen, P.; Pohkalainen, P.; Lalu, J. The Next Generation Motor Control Method: Direct Torque Control. EPE J. 1995, 5, 14-18. [CrossRef]

6. Grabowski, P.Z.; Blaabjerg, F. Direct Torque Neuro-Fuzzy Control of Induction motor Drive, DSP Implementation. In Proceedings of the 24th Annual Conference of the IEEE Industrial Electronics Society (Cat. No.98CH36200), Achen, Germany, 31 August-4 September 1998; pp. 657-661.

7. Hurst, K.D.; Habetler, T.G.; Griva, G.; Profumo, F. Zero Speed Tacho-less IM Torque Control: Simply a Matter of Stator Voltage integration. IEEE Trans. Ind. Appl. 1998, 34, 970-975. [CrossRef]

8. Lascu, C.; Boldea, I.; Blaabjerg, F. A Modified Direct Torque Control for Induction Motor Sensorless Drive. IEEE Trans. Ind. Appl. 1998, 1, 415-422.

9. Hajian, M.; Soltani, J.; Arab, G.R.; Hosseinnia, S. Input-Output feedback linearization of sensorless IM drives with stator and rotor resistances estimation. J. Power Electron. 2009, 9, 654-666.

10. Markadeh, G.R.A.; Yazdanpanah, R.; Soltani, J. Input-Output Feedback Linearization Control of Induction Motor with Adaptive Backstepping Observer. EPE J. 2008, 18, 33-40. [CrossRef]

11. Shokouhandeh, H.; Jazaeri, M.M. Robust design of fuzzy-based power system stabiliser considering uncertainties of loading conditions and transmission line parameters. IET Gener. Transm. Distrib. 2019, 13, 4287-4300. [CrossRef]

12. Boukas, T.K.; Habetler, T.G. High-performance induction motor speed control using exact feedback linearization with state and state derivative feedback. IEEE Trans. Power Electron. 2004, 19, 1022-1028. [CrossRef]

13. Lee, H.-D.; Kang, S.-J.; Sul, S.-K. Efficiency-Optimized Direct Torque Control of Synchronous Reluctance Motor Using Feedback Linearization. IEEE Trans. Ind. Electron. 1999, 46, 192-198.

14. Qutubuddin, M.D.; Yadaiah, N. Performance Evaluation of Neurobiologically Inspired Brain Emotional Adaptive Mechanism for Permanent Magnet Synchronous Motor Drive. Arab. J. Sci. Eng. 2021, 1, 1-19.

15. Kumar, G.V.; Chuang, C.H.; Lu, M.Z.; Liaw, C.M. Development of an electric vehicle synchronous reluctance motor drive. IEEE Trans. Veh. Technol. 2020, 69, 5012-5024. [CrossRef]

16. Ghorbani, S.; Unland, R.; Shokouhandeh, H.; Kowalczyk, R. An innovative stochastic multi-agent-based energy management approach for microgrids considering uncertainties. Inventions 2019, 4, 37. [CrossRef]

17. Heidari, H.; Rassõlkin, A.; Kallaste, A.; Vaimann, T.; Andriushchenko, E.; Belahcen, A.; Lukichev, D.V. A review of synchronous reluctance motor-drive advancements. Sustainability 2021, 13, 729. [CrossRef]

18. Zarchi, H.A.; Daryabeigi, E.; Markadeh, G.R.A.; Soltani, J. Emotional controller (BELBIC) based DTC for encoderless synchronous reluctance motor drives. In Proceedings of the 2011 2nd Power Electronics, Drive Systems and Technologies Conference, Tehran, Iran, 16-17 February 2011; pp. 478-483.

19. Shokouhandeh, H.; Jazaeri, M.; Sedighizadeh, M. On-time stabilization of single-machine power system connected to infinite bus by using optimized fuzzy-PID controller. In Proceedings of the 2014 22nd Iranian Conference on Electrical Engineering (ICEE), Tehran, Iran, 20-22 May 2014; pp. 768-773.

20. Heidari, H.; Rassõlkin, A.; Kallaste, A.; Vaimann, T.; Andriushchenko, E.; Belahcen, A. Design of a Research Laboratory Drive System for a Synchronous Reluctance Motor for Vector Control and Performance Analysis. Inventions 2021, 6, 64. [CrossRef]

21. De Martin, I.D.; Pasqualotto, D.; Tinazzi, F.; Zigliotto, M. Model-Free Predictive Current Control of Synchronous Reluctance Motor Drives for Pump Applications. Machines 2021, 9, 217. [CrossRef]

22. Dehkordi, B.M.; Parsapoor, A.; Moallem, M.; Lucas, C. Sensorless speed control of switched reluctance motor using brain emotional learning based intelligent controller. Energy Convers. Manag. 2011, 52, 85-96. [CrossRef]

23. Nagarajan, V.S.; Balaji, M.; Kamaraj, V.; Sivaramakrishnan, S.; Subash, K. Sensitivity Analysis and Design Optimization of Synchronous Reluctance and Permanent Magnet Motors. In Artificial Intelligence and Evolutionary Computations in Engineering Systems; Springer: Singapore, 2021; Volume 1, pp. 33-46.

24. Liu, Y.C.; Laghrouche, S.; N’Diaye, A.; Cirrincione, M. Hermite neural network-based second-order sliding-mode control of synchronous reluctance motor drive systems. J. Frankl. Inst. 2021, 358, 400-427. [CrossRef]

25. Dong, J.; Zhengming, Z.; Yao, D.; Wei, G. Position Sensorless Direct Torque Control of Synchronous Reluctance with Permanent Magnet Motor. In Proceedings of the 2006 CES/IEEE 5th International Power Electronics and Motion Control Conference, Shanghai, China, 14-16 August 2006; pp. 1-5.

26. Gercekcioglu, H.S.; Akar, M. Optimal rotor design of novel axial flux synchronous reluctance motor and validation. Int. Trans. Electr. Energy Syst. 2021, 31, e12866. [CrossRef]

27. Shokouhandeh, H.; Jazaeri, M. An enhanced and auto-tuned power system stabilizer based on optimized interval type-2 fuzzy PID scheme. Int. Trans. Electr. Energy Syst. 2018, 28, e2469. [CrossRef]

28. Xu, Z.; Rahman, M.F. Direct Torque and Flux Regulation of an IPM Synchronous Motor Drive Using Variable Structure Control Approach. IEEE Trans. Power Electron. 2007, 22, 2487-2498.

29. Himabindu, E.; Krishna, D.; Gopala, V.M. Performance of Intelligent Controller-Based Bearingless Switched Reluctance Motor. In Advances in Renewable Energy and Electric Vehicles; Springer: Singapore, 2021; Volume 767, pp. 355-373.

30. Pushparajesh, V.; Nandish, B.M.; Marulasiddappa, H.B. Hybrid intelligent controller based torque ripple minimization in switched reluctance motor drive. Bull. Electr. Eng. Inform. 2021, 10, 1193-1203. [CrossRef] 
31. Sriprang, S.; Poonnoy, N.; Guilbert, D.; Nahid-Mobarakeh, B.; Takorabet, N.; Bizon, N.; Thounthong, P. Design, Modeling and Differential Flatness Based Control of Permanent Magnet-Assisted Synchronous Reluctance Motor for e-Vehicle Applications. Sustainability 2021, 13, 9502. [CrossRef]

32. Ruba, M.; Jurca, F.; Czumbil, L.; Micu, D.D.; Martis, C.; Polycarpou, A.; Rizzo, R. Synchronous reluctance machine geometry optimisation through a genetic algorithm based technique. IET Electr. Power Appl. 2018, 12, 431-438. [CrossRef]

33. Yamashita, Y.; Okamoto, Y. Design optimization of synchronous reluctance motor for reducing iron loss and improving torque characteristics using topology optimization based on the level-set method. IEEE Trans. Magn. 2020, 56, 1-4. [CrossRef]

34. Kim, H.; Park, Y.; Oh, S.T.; Jang, H.; Won, S.H.; Chun, Y.D.; Lee, J.J. A Study on the Rotor Design of Line Start Synchronous Reluctance Motor for IE4 Efficiency and Improving Power Factor. Energies 2020, 13, 5774. [CrossRef]

35. Zhang, X.; Foo, G.H.B.; Vilathgamuwa, D.M.; Maskell, D.L. An Improved Robust Field-Weakeaning Algorithm for Direct-TorqueControlled Synchronous-Reluctance-Motor Drives. IEEE Trans. Ind. Electron. 2015, 62, 3255-3264. [CrossRef]

36. Yousefi-talouki, A.; Pellegrino, G. Vector control of matrix converter-fed synchronous reluctance motor based on flux observer. In Proceedings of the 2015 IEEE Workshop on Electrical Machines Design, Control and Diagnosis (WEMDCD), Turin, Italy, 26-27 March 2015; pp. 210-215.

37. Li, S.; Zhou, M.; Yu, X. Design and Implementation of Terminal Sliding Mode Control Method for PMSM Speed Regulation System. IEEE Trans. Ind. Inform. 2013, 9, 1879-1891. [CrossRef] 